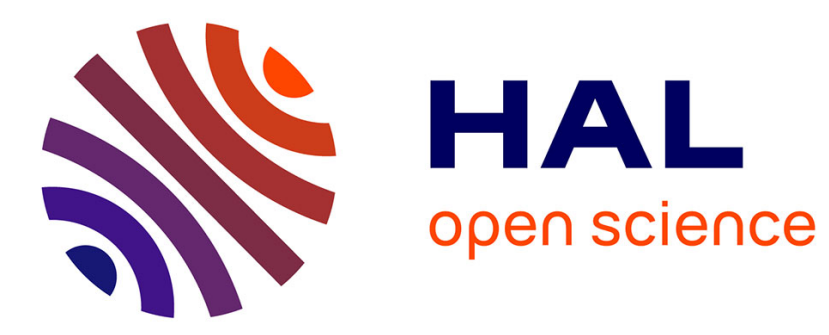

\title{
Experimental, computational, and in silico analysis of (C8H14N2)2[CdCl6] compound
}

I. Jomaa, O. Noureddine, S. Gatfaoui, N. Issaoui, Thierry Roisnel, H.

Marouani

\section{- To cite this version:}

I. Jomaa, O. Noureddine, S. Gatfaoui, N. Issaoui, Thierry Roisnel, et al.. Experimental, computational, and in silico analysis of (C8H14N2)2[CdCl6] compound. Journal of Molecular Structure, 2020, 1213, pp.128186. 10.1016/j.molstruc.2020.128186 . hal-02569944

HAL Id: hal-02569944

https://hal-univ-rennes1.archives-ouvertes.fr/hal-02569944

Submitted on 19 May 2020

HAL is a multi-disciplinary open access archive for the deposit and dissemination of scientific research documents, whether they are published or not. The documents may come from teaching and research institutions in France or abroad, or from public or private research centers.
L'archive ouverte pluridisciplinaire HAL, est destinée au dépôt et à la diffusion de documents scientifiques de niveau recherche, publiés ou non, émanant des établissements d'enseignement et de recherche français ou étrangers, des laboratoires publics ou privés. 


\section{Experimental, computational, and in silico analysis of $\left(\mathrm{C}_{8} \mathrm{H}_{14} \mathbf{N}_{2}\right)_{2}\left[\mathrm{CdCl}_{6}\right]$ compound}

Ikram Jomaa $^{\mathrm{a}}$, Olfa Noureddine ${ }^{\mathrm{b}}$, Sofian Gatfaoui ${ }^{\mathrm{a}}$, Noureddine Issaoui ${ }^{\mathrm{b}}$, Thierry Roisnel ${ }^{\mathrm{c}}$ and Houda Marouani ${ }^{\mathrm{a}}$

${ }^{a}$ Université de Carthage, Faculté des Sciences de Bizerte, LR13ES08 Laboratoire de Chimie des Matériaux, 7021, Bizerte,Tunisie

${ }^{\mathrm{b}}$ University of Monastir, Laboratory of Quantum and Statistical Physics LR18ES18, Faculty of Sciences, Monastir 5079, Tunisia

${ }^{c}$ Univ Rennes, CNRS, ISCR (Institut des Sciences Chimiques de Rennes) - UMR 6226, F-35000

Rennes, France

*Correspondence e-mail: houdamarouani2015@gmail.com

\section{Abstract}

The crystal structure of a novel compound $\left(\mathrm{C}_{8} \mathrm{H}_{14} \mathrm{~N}_{2}\right)_{2}\left[\mathrm{CdCl}_{6}\right]$ denoted $\left(\mathrm{MXDCdCl}_{6}\right)$ is discussed based on single crystal X-ray diffraction. This compound crystallizes in the triclinic system, with the space group $\mathrm{P} \overline{1}$ and the lattice parameters obtained are $a=7.5482(8) \AA, b=$ $8.495(1) \AA, \quad c=10.4656(12) \AA, \alpha=101.649(3)^{\circ}, \quad \beta=100.006(3)^{\circ}, \gamma=112.971(3)^{\circ}, V=$ 580.92(11) $\AA^{3}$ and $Z=1$.

The compound is built up from inorganic layers formed by $\mathrm{CdCl}_{6}{ }^{4-}$ anions and ammonium groups. The organic entities are located between these layers, and are linked to the anions through $\mathrm{N}-\mathrm{H} . . . \mathrm{Cl}$ and $\mathrm{C}-\mathrm{H} . . . \mathrm{Cl}$ hydrogen bonds generating a three-dimensional network, which stabilizes the crystal packing.

The surface mapped over the $\mathrm{d}_{\text {norm }}$ support the X-ray structural analysis and highlights the hydrogen bonds as the main intermolecular contacts. An infrared spectrum was registered to reveal the vibrational modes of the various characteristic groups of the title compound.

Optical property asserts a noteworthy band gap energy stating the stability of the resulting structure. The non-covalent interactions were studied through AIM and RDG analysis.

Subsequently, DFT and TD-DFT calculations were carried out to study the molecular structure, vibrational and electronic properties of the investigated molecule.

In silico investigation was performed via molecular docking analysis to explore the anticipated antibacterial activity possessed in the title compound.

Keywords: Bis(m-xylylenediaminium) hexachlorocadmate(II); X-ray diffraction; DFT calculations; IR spectroscopy; Hirshfeld surface; Molecular docking. 


\section{Introduction}

The assembly of both organic and inorganic materials was the take off way to promote new sophisticated hybrid compounds with targeted physical and chemical characteristics. The hybrid nature of these compounds gives them not only intermediate properties between the mineral and the organic but also new behaviors, astonishing composition, and diversity of exceptional structure in more suitable materials. The properties of interest in these materials open up a wide field of application in numerous domain such as biology $[\mathbf{1 , 2}]$, optics, electrical conductivity, photochemistry $[3,4]$, medicine $[\mathbf{5 , 6}]$, and photo catalysis [7] to mention just a few.

Among these materials, Xylylenediamine and its derivatives have been of great interest due to their possessing of valuable pharmacological properties [8], which have been evaluated by antimicrobial studies against various bacteria and fungi species, cytotoxicity against cancer cells and good antioxidant activity [9]. On the other hand, chlorocadmates(II) crystal chemistry is extremely diverse and complex, it exhibits structural flexibility, manifested by a wide variety of geometries and stoichiometries such as $\mathrm{CdCl}_{3}{ }^{-}, \mathrm{CdCl}_{4}{ }^{2-}$, $\mathrm{CdCl}_{5}^{3-}, \mathrm{CdCl}_{6}^{4-}, \mathrm{Cd}_{3} \mathrm{Cl}_{10}{ }^{4-}$, etc [10]. Furthermore, octahedral coordination of $\mathrm{Cd}^{\mathrm{II}}$ is essentially present in polymeric chlorocadmates [11-12].

Particularly, m-xylylenediamine organic molecules where the two ammonium groups are in meta position can be associated with chlorocadmates to produce systems with a potentially forceful network of hydrogen bond interactions.

In the present contribution to the above materials, we report the crystal structure study in detail of a novel material, $\left(\mathrm{C}_{8} \mathrm{H}_{14} \mathrm{~N}_{2}\right)_{2}\left[\mathrm{CdCl}_{6}\right]$. The compound has been characterized by $\mathrm{X}$ ray diffraction, to determine the crystallographic characteristics and atomic arrangements.

Besides, Hirshfeld surfaces analyses and fingerprints plots calculations have been investigated to clarify the nature of the intermolecular interactions. Furthermore, vibrational and optical measurements were also reported.

Theoretical studies using Time-dependent DFT and DFT calculations have been combined with experimental results throughout this work for structural, vibratory and electronic characterization. Frontier orbitals (HOMO-LUMO), topological properties and RDG analysis were obtained computationally.

Due to the different potential biological activity of the title compound and since a recent docking study have been conducted with the same organic cation [9], we studied the 
docking characteristics with various bacteria: Escherichia coli (6G9P), Pseudomonas aeruginosa (2W7Q), Pseudomonas exotoxin (1XK9), Klebsiellapneumoniae (5O77), Enterococcus faecalisAhpC (5Y63), Staphylococcus epidermidis (3KP3), Bacillus subtilis (4OYH) and Enterococcus faecalis FIC (5NV5). Results reveal that these bacteria are classified into two parts: five Gram-negative bacteria: 6G9P, 2W7Q, 1XK9, $5 \mathrm{O} 77$ and 5Y63; and three Gram-positive bacteria: 3KP3, 4OYH and 5NV5.

\section{Experimental details}

\subsection{Synthesis and crystallization}

Stoichiometric solutions of $m$-xylylenediamine dissolved in ethanol and $\mathrm{CdCl}_{2} \cdot \mathrm{H}_{2} \mathrm{O}$ mixed in dilute $\mathrm{HCl}(10 \mathrm{~mL}, 1 \mathrm{M})$ were added together and stirred for several minutes to yield a homogeneous assortment of solution.

Well-defined colorless and prisms single crystals of $\mathrm{MXDCdCl}_{6}$ were formed as the solvent slowly evaporated within a few days at room temperature then isolated and subjected to X-ray diffraction analysis. Schematically the reaction can be written as follow:

$$
2 \mathrm{C}_{8} \mathrm{H}_{12} \mathrm{~N}_{2}+\mathrm{CdCl}_{2} \cdot \mathrm{H}_{2} \mathrm{O}+4 \mathrm{HCl} \stackrel{\mathrm{ErOH} / \mathrm{H}_{2} \mathrm{O}}{\longrightarrow}\left(\mathrm{C}_{8} \mathrm{H}_{14} \mathrm{~N}_{2}\right)_{2} \mathrm{CdCl}_{6}+\mathrm{H}_{2} \mathrm{O}
$$

\subsection{Investigation techniques}

\subsubsection{X-ray data collection}

The intensity data were collected at $150 \mathrm{~K}$ using a D8 VENTURE Bruker-AXS diffractometer equipped with Multilayer monochromator and MoK $\alpha$ radiation $(\lambda=0.71073$ $\AA$ ). Absorption corrections were performed using the multi-scan technique using the SADABS program [13]. The total number of measured reflections was 13112 among which 2661 were independent and 2630 had the intensity $\mathrm{I}>2 \sigma(\mathrm{I})$.

The structure was solved by direct methods using SHELXS-97, which revealed the position of all non-hydrogen atoms, and then refined with full-matrix least-square methods based on $\mathrm{F}^{2}$ (SHELXL-97) [14] included in the WINGX program [15].

A final refinement on $\mathrm{F}^{2}$ converged at $\mathrm{R}\left(\mathrm{F}^{2}\right)=0.016$ and $\mathrm{w} R\left(\mathrm{~F}^{2}\right)=0.045$. A summary of the crystallographic data and the structure refinements are given in Table 1. An ORTEP drawing of the molecular arrangement is exposed in Fig. 1.

Supporting data (CIF files) have been deposited in the Cambridge Crystallographic Data centre as supplementary materials $\mathrm{N}^{\circ}$ CCDC 1962252. Copies of the data can be obtained, free of charge via www.ccdc.cam.ac.uk/data_request/cif or from the Cambridge 
Crystallographic Data Centre, 12 Union Road, Cambridge CB21EZ, UK; or by email to deposit@ccdc.cam.ac.uk.

\subsubsection{Physical measurements}

IR spectrum was recorded at room temperature in the frequency range 4000-400 $\mathrm{cm}^{-1}$ with a Perkin-Elmer FT-IR 1000 spectrometer using the technique of pellets with $\mathrm{KBr}$ as a dispersant.

Solid state UV-Vis spectrum was registered with a Perkin-Elmer Lambda 35 spectrophotometer in the range of $200-800 \mathrm{~nm}$.

\subsection{Computational details}

Initially, the structure of $\mathrm{MXDCdCl}_{6}$ compound was modeled with the GaussView program [16] and, then this form was optimized in the gas phase with the Gaussian 09 software package [17] by using the Density functional theory (DFT) with the Becke-threeparameter hybrid exchange functional combined with the Lee-Yang-Parr correlation functional (B3LYP) [18,19] levels, the 6-311++G(d,p) basis set was used for all atoms except for the cadmium atom, the LANL2DZ basis set and effective core potentials (ECPs) have been used in order to represent the metal. All the calculations have converged to an optimized geometry that corresponds to the lowest energy. Positive vibrational frequencies obtained confirming the stability of the optimized geometries.

The vibrational assignments were performed considering the potential energy distribution components $(\mathrm{PED}) \geq 10 \%$ using the VEDA4 package. The GaussView molecular visualization program [20] was used to verify the assignments of the bands.

To analyze the interactions in the crystal, Hirshfeld surfaces mapped with $d_{\text {norm }}$ and their associated 2D fingerprint presented in this paper were plotted using Crystal Explorer version 3.1 software [21] imported on a CIF file. The topological properties at the BCPs were determined with the Multiwfn program [22] while the reduced density gradient of the title molecule are graphed by Multiwfn and plotted by the VMD program [23].

The reactivity was predicted by using the frontier molecular orbitals (FMOs) [24] together with prominent descriptors computed by means of equations reported in the literature [25-27] at DFT/LANL2DZ level. The (FMOs) was visualized with the Gauss View software. The UVVisible spectrum was predicted in aqueous solution by using Time-dependent DFT calculations TD-DFT/ LANL2DZ at the B3LYP and the BLYP levels with the Gaussian 09 program [17]. 
The docking calculations were carried out using iGEMDOCK [28] program. The crystalline structures of bacteria are illustrated from the Research Collaboratory for Structural Bioinformatics (RCSB) Protein Data Bank (PDB) [29]. Using ZINC database [30], we choose the ligand associated with these bacteria. We note that Discovery Studio Visualizer makes it possible to obtain the visual representations for the best conformations of docking, whose setting is as follows: population size 800 , generations 80 and number of solutions 10 .

\section{Results and discussion}

\subsection{X-ray diffraction and geometry optimization}

The asymmetric unit of the title material depicted in an ORTEP drawing, takes in one dication doubly protonated at the $\mathrm{N} 1$ and $\mathrm{N} 2$ nitrogen atoms, and one-half of a $\left[\mathrm{CdCl}_{6}\right]^{4-}$ anion, located on an inversion center (Fig.1a).

The packing of $\left(\mathrm{C}_{8} \mathrm{H}_{14} \mathrm{~N}_{2}\right)_{2}\left[\mathrm{CdCl}_{6}\right]$, viewed along the $a$-axis (Fig. 2a), shows that the compound is built up by a succession of cationic and anionic layers which alternate along the $c$-axis, the organic cations are distributed around the $\mathrm{z}=1 / 2$ planes. These layers are held together by hydrogen bonds types $\mathrm{N}-\mathrm{H}$... $\mathrm{Cl}$ and $\mathrm{C}-\mathrm{H}$... Cl where all the chlorine atoms involve as acceptors to form an infinite three-dimensional network (Fig. 2b). The same stacking interactions were also observed between the $m$-xylylenediaminium cations and the corresponding halometalate anions [31].

Interatomic bond lengths and angles of the $\left[\mathrm{CdCl}_{6}\right]^{4-}$ anion (Table 2) are typical of sixcoordinated $\mathrm{Cd}(\mathrm{II})[\mathbf{3 2}, 33]$. The calculated average values of the distortion indices [34] corresponding to the different angles and distances in the $\mathrm{CdCl}_{6}$ octahedron $[\mathrm{DI}(\mathrm{CdCl})=$ $0.01721, \mathrm{DI}(\mathrm{ClCdCl})=0.0073$ and $\mathrm{DI}(\mathrm{ClCl})=0.0079]$ show a large distortion of the $\mathrm{CdCl}$ distances if compared to the $\mathrm{ClCl}$ distances and $\mathrm{ClCdCl}$ angles.

Assessment of the organic geometrical features shows that the m-xylylenediammonium cation exhibits a normal spatial configuration with ( C-C, C-N) distances and (C-C-C, N-C-C) angles quite similar to those found in other compounds involving the same organic groups [35-37]. The aromatic ring of the cation is essentially planar with an r.m.s. deviation of $0.0015 \AA$.

Organic cations are also connected together via $\mathrm{C}-\mathrm{H} \ldots \pi$ interactions forming subsequently infinite chains spreading along the b-axis (Fig. 2c). 
Inside this arrangement, (Fig. 2d) the entities are interconnected via multiple hydrogen bonds generate rings forming $\mathrm{R}_{2}{ }^{2}(5), \mathrm{R}_{4}{ }^{2}(8)$ and $\mathrm{R}_{3}{ }^{2}(6)$ motifs (Details in Table 3 ).

The optimized molecular structure of $\mathrm{MXDCdCl}_{6}$ compound is given in Fig. 1b. A comparison between selected optimized geometrical parameters, with experimental X-ray crystallographic parameters, is given in Table 2.

Examination of the organic cation reveals that the calculated values of binding lengths of the aromatic ring are almost identical to those observed experimentally by X-ray diffraction. The variation of the optimized bond length of aromatic $\mathrm{C}-\mathrm{C}$ is from $1.40 \AA$ to $1.41 \AA$. The linkage lengths of the methyl groups bound to $\mathrm{N}$ are, N8-C23 $=1.50 \AA$ and $\mathrm{N} 9-\mathrm{C} 18=1.52 \AA$, which are close to the observed XRD values of about 1.49. The C-C-C binding angles forming the m-xylylenediammonium ring were calculated between $119.06^{\circ}$ and $120.90^{\circ}$. These values do not differ greatly from those observed by X-ray diffraction.

For the anionic group, the values of the experimental and the calculated bond length of $\mathrm{Cd}-\mathrm{Cl}$ spread in the ranges 2.5849(4) - 2.7177(4) $\AA$ and 2.7717 - $2.8012 \AA$, respectively. As well, the $\mathrm{Cl}-\mathrm{Cd}-\mathrm{Cl}$ binding angles are calculated between $88.5537^{\circ}$ and $91.4463^{\circ}$, and varying from $87.913(11)^{\circ}$ to $92.087(11)^{\circ}$ for the observed XRD values. We have observed that the optimized bond lengths and binding angles are slightly different from those observed experimentally by X-ray diffraction. This difference is due to that the theoretical calculations were performed in the gas phase where the molecules are isolated while experimental results belong to molecules in solid-state, where the crystal structure is related to intermolecular interactions, despite that the optimized parameters represent a good approximation.

\subsection{Hirshfeld surface investigation}

For visualization, quantification and exploration of intermolecular close contacts present within a crystal structure, Hirshfeld surface [38] and their associated 2D fingerprint plots [39] were used, measured through the CrystalExplorer 3.1 program [20]. The Hirshfeld $d_{\text {norm }}$ surfaces of the title compound are shown in Fig. 3 where the bright red spots indicate the existence of $\mathrm{N}-\mathrm{H} \ldots \mathrm{Cl}$ and $\mathrm{C}-\mathrm{H} \ldots \mathrm{Cl}$ hydrogen bonding and the $\mathrm{H} \ldots \mathrm{H}$ and $\mathrm{C} \ldots \mathrm{H} / \mathrm{H} \ldots \mathrm{C}$ contacts are located in the blue and white areas respectively [40]. Examining 2D graphs shown in Fig. 4 highlights atoms involved in close contact and allows us to connect numeric values to previously described surfaces.

For the compound, $\mathrm{H}$...Cl/Cl...H contacts that are attributed to $\mathrm{N}-\mathrm{H}$...Cl and $\mathrm{C}-\mathrm{H}$...Cl hydrogen-bonding interactions have the most significant percentage contributions to the 
surface of Hirshfeld $67.3 \%$ and appear as two symmetrical wings with two long and narrow points at a maximum sum of $d_{e}+d_{i} \sim 2.2 \AA$ less than the sum of van der Waals radii of involvedatoms $(1.75+1.09=2.84)$; it affirms that the inter-contact are considered close.

The H...H contacts comprise $21.5 \%$ of the entire surface of Hirshfeld appear in the middle of the scattered points in the two-dimensional fingerprint maps by two weak peaks around de $+\mathrm{di} \sim 2.4 \AA$, a value greater than the sum of the van der Waals radii of the atoms of hydrogen $(1.09+1.09=2.18 \AA)$. This reveals the absence of close H...H contacts.

The contacts C...H / H...C cover $10 \%$ of the overall surface of Hirshfeld show on its 2D graph the presence of a symmetric pair of wings around a sum $\left(d_{e}+d_{i} \sim 2.7 \AA\right)$ less than the sum of the van der Waals radii of the carbon and hydrogen atoms $(2.79 \AA)$. These contacts are considered as being close contacts.

The C...C contacts, which represent only $0.9 \%$ of the Hirshfeld surface with $\left(d_{e}+d_{i}\right.$ $\sim 3.6 \AA$ ) greater than the sum of the van der Waals radii of the carbon atoms (3.4 $\AA$ ) reveals the absence of close C...C contacts and therefore no $\pi-\pi$ interactions in our crystalline stacking [41]. Such illustration study for intermolecular contacts is coherent with the results observed by crystallography investigation.

\subsection{Vibrational IR spectra and assignments}

Herein, we discussed the vibrational properties of the $\mathrm{MXDCdCl}_{6}$ molecule by conducting a vibratory study using experimental and calculated infrared spectroscopy. The experimental IR spectrum measured between 400 and $4000 \mathrm{~cm}^{-1}$ and the simulated one using B3LYP/LanL2DZ basis set are shown in Fig. 5 in this figure we observed good correlations among the experimental and the predicted spectra. The experimental infrared wavenumber and the calculated one from DFT method assigned by VEDA program [44] and GaussView software [16] are provided in Table 4 along with a tentative assignment of the observed bands essentially based on comparisons with data previously reported for similar compounds [9]. This table shows that there is a slight difference between the experimental values and the calculated frequencies, these small differences are due, in the experimental process we recorded spectra in the solid phase sample where the crystalline packing was not considered while the DFT calculations were carried out with an isolated molecule and in the gas phase. Brief discussions of the assignments for the most important groups are presented below.

\subsubsection{Vibrations of hexachlorocadmate(II) anion}


Based essentially on comparison with the literature for numerous chlorocadmate compounds $[43,44]$, and according to the DFT calculations it is found that all bands originating from vibrations of $\mathrm{CdCl}_{6}^{4-}$ anions are observed below $500 \mathrm{~cm}^{-1}$. The asymmetric and symmetric stretching of $\mathrm{Cd}-\mathrm{Cl}$ appeared at 193 and $171 \mathrm{~cm}^{-1}$, respectively.

The band corresponding to the bending mode of $\mathrm{H}-\mathrm{Cl}-\mathrm{Cd}$ appeared in the $74 \mathrm{~cm}^{-1}$.

\subsection{2. m-xylylenediammonium vibration}

Concerning the organic entity, the high-frequency region between 3439 and $3112 \mathrm{~cm}^{-1}$ is assigned to the $\mathrm{N}-\mathrm{H}$ asymmetric and symmetric stretching vibration. The DFT computations give the frequency of these bands between 3455 and $3012 \mathrm{~cm}^{-1}$.

The bands between 1634 and $1476 \mathrm{~cm}^{-1}$ are attributed to the $\mathrm{C}=\mathrm{C}$ stretching vibration of the aromatic ring and to the characteristic $\mathrm{NH}_{3}{ }^{+}$asymmetric and symmetric stretching vibrations. The corresponding bands are calculated to be found at 1663 and $1485 \mathrm{~cm}^{-1}$.

In m-xylylenediaminium bis(perchlorate) monohydrate [45] these modes are observed nearly in the same region. The band exhibited at $2730 \mathrm{~cm}^{-1}$ is due to the aromatic $\mathrm{C}-\mathrm{H}$ stretching vibration and predicted at $2990 \mathrm{~cm}^{-1}$. The bands at 983 and $907 \mathrm{~cm}^{-1}$ in the experimental spectrum correspond to the C-N stretching. The same vibration is calculated between 1035 and $958 \mathrm{~cm}^{-1}$ by DFT level. The $\mathrm{C}-\mathrm{H}$ in-plane bending vibration and the $\mathrm{C}-\mathrm{H}$ out of plane bending vibration are observed at $1165 \mathrm{~cm}^{-1}$ and $1095 \mathrm{~cm}^{-1}$ respectively and predicted at 1212 $\mathrm{cm}^{-1}$ at $1043 \mathrm{~cm}^{-1}$. The spectral domain between 547 and $455 \mathrm{~cm}^{-1}$ is ascribed to the out of plane vibration modes of the $\mathrm{C}-\mathrm{C}$ and $\mathrm{C}=\mathrm{C}$ groups. This was calculated to be found in region $645-479 \mathrm{~cm}^{-1}$.

\subsection{AIM topological analysis}

The topological properties related to Atoms-In-Molecule (AIM) approach [46] are useful to elucidate the type of interactions present within a molecule and therefore we foretell its stability [47-49]. According to AIM theory each chemical bond possesses a critical point of binding denoted BCP defined as being a minimum of electronic density along the connecting path and a maximum in the other two perpendicular directions.

Several energetic and topological parameters can be defined after the location of the BCP to evaluate the properties of the bonds in the title compound, and in particular, the hydrogen bonds.

The graphical representation of the AIM analysis using Multiwfn program [21] at LANL2DZ level of $\left(\mathrm{C}_{8} \mathrm{H}_{14} \mathrm{~N}_{2}\right)_{2} \mathrm{CdCl}_{6}$ compound and of its corresponding cation is illustrated respectively in Fig. 6 and Fig. 7, while the corresponding geometrical, energetic and topological parameters are listed in Table $\mathbf{S 1}$ and Table $\mathbf{S 2}$. 
The AIM analysis reveals that our material is stabilized by eight hydrogen bonds that meets Koch and Popelier criteria [50] and that $\mathrm{H} 17 \ldots \mathrm{Cl} 3, \mathrm{~N} 8 \ldots \mathrm{Cl} 2, \mathrm{H} 27 \ldots \mathrm{Cl} 3, \mathrm{H} 28 \ldots \mathrm{Cl} 7$ interactions present symmetrical topological properties to $\mathrm{H} 52 \ldots \mathrm{Cl} 4, \mathrm{~N} 32 \ldots \mathrm{Cl} 5, \mathrm{H} 51 \ldots \mathrm{Cl}$, $\mathrm{H} 41$...Cl6 interactions. The G/ $\rho$ ratio is also used to characterize the type of interaction. This ratio must be greater than 1.0 to confirm the existence of hydrogen bonds [46]. This is the case in the present work.

According to the BCP analysis of Table S1 and Based on the Rozas et al. [51] criterion all of the eight hydrogen bonds are considered weak since the Laplacian and the energy density values are positive.

Positive Laplacian values indicate as well the depletion of electronic charge along the liaison path, the density observed is in the range of 0.00601 and 0.01300 a.u the highest value is for the $\mathrm{H} 27 \ldots \mathrm{Cl} 3$ or $\mathrm{H} 51 \ldots \mathrm{Cl} 6$ interactions (0.01300 a.u) probably because the distance between those two atoms is the lowest.

In Fig. 8, the C-H... $\pi$ interactions between the two cations are very quietly visible from the position of the three BCPs that link this two latter, AIM analysis allows us to detect the presence of the cage character with the presence of cage critical points (CCPs) and the cyclic character in a molecular system with the presence of ring critical points (RCPs), as shown as well in Fig. 9.

The ellipticity value provides an idea about the accumulation of charges in a given plane here the very low value $(\varepsilon=-1.4260,-1.3921)$ at the RCP points confirms that there is delocalization of electron in aromatic nucleus.

\subsection{Reduced density gradient (RDG) analysis}

The existing non-covalent interactions (NCIs) in $\mathrm{MXDCdCl}_{6}$ compound have been also validated and evaluated by an NCI descriptor introduced by Johnson et al. [52] and ContrerasGarcia et al. [53] based on the electronic density and its first derivative named RDG. The reduced electron density gradient (RDG) provides clear fingerprints of various kinds of NCIs and it is defined by the following equation.

$$
\operatorname{RDG}(\mathrm{r})=\frac{1}{2\left(3 \pi^{2}\right)^{1 / 3}} \frac{\mid \nabla \rho(x)]}{\rho(v)^{4} / 3}
$$

When the quantity $\rho(r) \operatorname{sign}\left(\lambda_{2}\right)$ is mapped onto the RDG isosurface, it enables one to highlight the attractive or repulsive nature of the interactions and to rank their relative strength on a qualitative, visual basis. 
According to the sign of the second largest eigen value $\lambda_{2}\left(\lambda_{1} \leq \lambda_{2} \leq \lambda_{3}\right)$ of the ED Hessian matrix at each isosurface point:

- If $\lambda_{2}<0$ : Attractive and binding interactions (hydrogen bonds).

- If $\lambda_{2}>0$ : repulsive and non-binding interactions (steric effect in ring and cage).

- If $\left(\lambda_{2} \approx 0\right)$ : van der Waals interactions.

The results were performed and plotted respectively by the use of Multiwfn and VMD Programs [21,22]. These results were collected in Figs. 8a and $\mathbf{8 b}$ for the entire compound and in Figs. 9a and $9 \mathbf{b}$ for the corresponding cation.

According to Fig. 8a, the attractive, van der Waals and repulsive interactions in the $\mathrm{MXDCdCl}_{6}$ structure appear respectively as blue, green and red spikes.

The RDG peaks toward -0.031 of sign $\left(\lambda_{2}\right) \rho$ correspond to a strong attractive interaction confirmed as well by the low density values.

Turning to Fig. $\mathbf{8 b}$, clear blue spots are checked between the hydrogen and chlorine atoms, which signify the strong attractive interaction $\mathrm{N}-\mathrm{H} . . \mathrm{Cl}$ and $\mathrm{C}-\mathrm{H} . . . \mathrm{Cl}$. The interactions appear in the form of green plates are attributed to van der Waals interactions. The elliptic red plate located at the center of the aromatic nucleus is related to repulsive interactions which show a strong steric effect.

NCIs encompass a wide range of bonding types, such as hydrogen and halogen bonds, CH... $\pi$ interactions, and several binding (or anti-binding) forces, like those due to dispersion, or to electrostatics. Fig. 9 b shows a C-H... $\pi$ type intermolecular interaction similar to those found in benzene [54] since a large RDG surface appears that encompasses the whole region between the two facing aromatic rings.

In Fig. 9a three out of five spikes maintained confirming as well the repulsive interactions between the aromatic nucleus and the C-H... $\pi$ intermolecular interaction.

The results of the NCI descriptor provide a complimentary picture to that offered by AIM calculation.

\section{6. $U$ V absorption of $\left(\mathrm{C}_{8} \mathrm{H}_{14} \mathrm{~N}_{2}\right)_{2}\left[\mathrm{CdCl}_{6}\right]$}

The predicted UV-Visible spectra of $\mathrm{MXDCdCl}_{6}$ by using TD-DFT/ LANL2DZ method at the B3LYP and the BLYP level of theory with the Gaussian 09 program [17] are compared in Fig.10 the differences are attributed to the calculations and to the basis set. The corresponding experimental UV-Visible spectrum in solid-state is given in Fig.11a, the title compound exhibits only one band centered at $355 \mathrm{~nm}$ that corresponds to $\pi-\pi^{*}$ transitions, which is 
relative to the aromatic conjugation in the cations according to the literature [9] and to the ligand to metal charge transfer LMCT confirmed by a weak absorption of the spectrum. This feature is typical of similar chlorocadmate materials [43] and varies with the coordination number.

This band is observed in the BLYP level calculated spectrum at $373 \mathrm{~nm}$ due to the electronic transition from HOMO-2 $\rightarrow$ LUMO+1 (100\%) molecular orbitals, and for the B3LYP level at $260 \mathrm{~nm}$ due to the electronic transition from HOMO-3 $\rightarrow$ LUMO $(90 \%)$ molecular orbitals. The calculated absorption wavelength $\lambda$, excitation energies $\mathrm{E}$ along with oscillator strengths $f$ for the $\left(\mathrm{C}_{8} \mathrm{H}_{14} \mathrm{~N}_{2}\right)_{2} \mathrm{CdCl}_{6}$ using TD-DFT/ BLYP/LANL2DZ method and TD-DFT/ B3LYP/LANL2DZ method in Water solvent are presented respectively in Table S3 and Table S4.

The evaluated band gap of our compound was found to be $2.98 \mathrm{eV}$ according to the Tauc plot model [55], (see Fig. 11.b) suggesting that the crystal may possess dielectric behavior to induce polarization when powerful radiation is incident on the material [56].

\subsection{HOMO-LUMO analysis}

In order to study the stability and chemical reactivity of the molecule, the frontier molecular orbitals (FMOs) analyses have been performed. Conceptual molecular orbital calculations were applied to evaluate the spatial separation of FMOs in mXylylenediammonium. The energy difference between the HOMO (Highest Occupied Molecular Orbital) and LUMO (Lowest Unoccupied Molecular Orbital) frontier orbitals called «gap» is an excellent indicators of electron transfer in molecular systems [23]. In our case, the evaluation of the gap energy value is important regarding the antioxidant, antibacterial and antifungal activities associated with m-Xylylenediammonium compound [9].

The HOMO and LUMO graphics that can be easily observed by using Gauss View program [16] are given in Fig. 12. Orbital analysis revealed that HOMO components are localized on the anionic part, while the LUMO components are mainly located on the organic cation. These findings manifest that the electrons are delocalized in the inorganic part $\left[\mathrm{CdCl}_{6}\right]^{4-}$, the space of energy between HOMO-LUMO molecular orbitals calculates $3.17 \mathrm{eV}$ is an index of high kinetic stability and low chemical reactivity, because it is energetically unfavorable to add electron to a high-lying LUMO or to extract electrons from a low-lying HOMO [57]. 


\subsection{Global reactivity descriptors}

Through the results of the HOMO and LUMO calculated energies and adequate equations, we can set the global chemical reactivity descriptors that are necessary to predict the behavior of the title molecule [25-26].

The reactivity parameters settings are as follows: the hardness $\eta: \eta=(I-A) / 2$, where $A$ is the ionization potential and $\mathrm{I}$ is the electron affinity [ $\mathrm{A}=-\mathrm{E}_{\mathrm{LUMO}}, \mathrm{I}=-\mathrm{E}_{\mathrm{HOMO}}$ ], the word "hardness" means resistance to deformation or change specifically resistance of the chemical potential to change in the number of electrons [58-59]. Softness is the opposite of hardness: a low value of $\eta$ means high softness defined by $S: S=1 / 2 \eta$; the chemical potential $\mu: \mu=-(I+$ A) $/ 2$, the electronegativity $\chi: \chi=(I+A) / 2$ [60] and the electrophilicity index $\omega: \omega=\mu^{2} / 2 \eta$ [61].

The values obtained of $\left(\mathrm{C}_{8} \mathrm{H}_{14} \mathrm{~N}_{2}\right)_{2} \mathrm{CdCl}_{6}$ compound by using DFT method are summarized in Table S5. Since the DFT/ LANL2DZ level gave an energy value $3.17 \mathrm{eV}$ very close to that found with the Tauc model unlike the DFT method. Thus, these results clearly evidence that the basis set has remarkable influence on the reactivities and behaviors of the species [62]. Table S5 shows that all determined energies are negative as well as the chemical potential, so we can conclude that the crystal structure is stable and does not decompose spontaneously into its elements [63-64].

The conclusion can be drawn of this part, is that the gap value indicates that this compound is definitely stable but can be quite reactive with higher $\eta$ and low $S$.

\subsection{Molecular docking}

The main objective of ligand-protein docking is to provide the binding mode of a ligand with a protein containing a three-dimensional structure [65-66]. Using iGEMDOCK program, the best-docked poses of $\left(\mathrm{C}_{8} \mathrm{H}_{14} \mathrm{~N}_{2}\right)_{2} \mathrm{CdCl}_{6}$ compound with eight bacteria: 6G9P, 2W7Q, 1XK9, 5O77, 5Y63, 3KP3, 4OYH and 5NV5 have been determined and represented in Fig. 13. To study the interactions between ligand and protein in more details, we have summarized in Table 5 the energetic results of docking calculations. Note that these best poses and these interaction energies have physical, biological and pharmaceutical interests. 10 poses are found during the docking calculations. We only present the best pose that is referring to minimal energy. This minimal energy is the sum of three interaction energies (VDW, H-bond and electronic binding energies). As it is shown in Table 5, 1XK9 was found to be the strongest binding bacteria with an energy equal to $-92.702 \mathrm{kcal} / \mathrm{mol}$. Likewise, she owns the strongest van der Waals (VDW) interaction $(E=-92.534 \mathrm{kcal} / \mathrm{mol})$. While, the 5077 is the weakest 
binding bacteria and also it forms the weakest VDW interaction $(\mathrm{E}=-72.670 \mathrm{kcal} / \mathrm{mol})$. We notice that the binding energies of 5Y63 and 1XK9 bacteria are very close with average energy equal to $-92.554 \mathrm{kcal} / \mathrm{mol}$. Same thing for $5 \mathrm{NV} 5$ and $3 \mathrm{KP} 3$ whose total energies scores equal to $-89.613 \mathrm{kcal} / \mathrm{mol}$ and $-89.093 \mathrm{kcal} / \mathrm{mol}$, respectively.

We represent in Fig. 14, several forms of intermolecular interactions between $\left(\mathrm{C}_{8} \mathrm{H}_{14} \mathrm{~N}_{2}\right)_{2} \mathrm{CdCl}_{6}$ ligand and the strongest binding bacteria 1XK9. For more details, Fig. S1 shows all the interactions between $\left(\mathrm{C}_{8} \mathrm{H}_{14} \mathrm{~N}_{2}\right)_{2} \mathrm{CdCl}_{6}$ and other bacteria. We notice, from these results, the existence of $\pi-\pi$ stacking interactions. This type of interaction presents many applications in the biomedical and biotechnological fields [67]. They have been applied as a driving force for drug loading. There are also pi-alkyl interactions. Typically in these interactions, there is a crystal cloud interaction on an aromatic group and a group of electrons of any alkyl group. According to these results, we can conclude that $\left(\mathrm{C}_{8} \mathrm{H}_{14} \mathrm{~N}_{2}\right)_{2} \mathrm{CdCl}_{6}$ compound have antibacterial activity. It plays an important role in drug discovery against these diseases. As we have seen in Table 5, $\left(\mathrm{C}_{8} \mathrm{H}_{14} \mathrm{~N}_{2}\right)_{2} \mathrm{CdCl}_{6}$ present revealing inhibition activity against $1 \mathrm{XK} 9,5 \mathrm{Y} 63,5 \mathrm{NV} 5$ and $3 \mathrm{KP} 3$ bacteria. He also has an interesting inhibition activity against 4OYH, 6G9P, 2W7Q and 5O77. So, we can conclude that this compound can be considered as a potent inhibitor against these bacteria.

\section{Conclusion}

A Single crystal of $\left(\mathrm{C}_{8} \mathrm{H}_{14} \mathrm{~N}_{2}\right)_{2}\left[\mathrm{CdCl}_{6}\right]$ was grown at room temperature by the slow solvent evaporation method. The structural arrangement can be described as an alternation of organicinorganic layers supported by means electrostatic, H-bonds type $\mathrm{N}-\mathrm{H} \ldots \mathrm{Cl}$ and $\mathrm{C}-\mathrm{H}$...Cl, CH... $\pi$ and van der Waals interactions. The Hirshfeld surface analysis reveals the percentage of intermolecular contacts of the title compound and shows that the major part of the Hirshfeld surface is occupied by the contacts $\mathrm{H}$... Cl/Cl...H.

The vibrational properties of this structure were studied by infrared spectroscopy and the assignment of the vibrational bands was performed by comparison with the vibration modes frequencies of homologous compounds.

The studies of optical activities in solid-state confirm the semiconductor behavior of this material with a significant band gap at $2.39 \mathrm{eV}$.

Structural and spectroscopic properties (IR and UV-Vis) were presented as well via TD-DFT and DFT calculations. The comparison between both theoretical and experimental methods shows a good agreement. The non-covalent interactions were studied through AIM and RDG analysis. The Orbital analysis revealed that HOMO components are localized on the anionic 
part, while the LUMO components are mainly located on the organic cation. Furthermore, the docking study shows that the compound might exhibit antibacterial activity.

\section{Acknowledgements}

We are grateful to the Tunisian Ministry of Higher Education Scientific Research for the provided financial support.

\section{References}

[1] L.M. Novena, S.S. Kumar, S. Athimoolam, Improved solubility and bioactivity of theophylline (abronchodilator drug) through its new nitrate salt analyzed by experimental and theoretical approaches, J. Mol. Struct. 1116 (2016) 45-55.

[2] A. Müller, F. Peters, M.T. Pope, D. Gatteschi, Polyoxometalates: very large clustersnanoscalemagnets, Chem. Rev. 98 (1998) 239-272.

[3] P. Englebienne, A.V. Hoonacker, Gold-conductive polymer nanoparticles: a hybrid material with enhanced photonic reactivity to environmental stimuli, J. Colloid Interface Sci. 292 (2) (2005) 445-454.

[4] A. Müller, H. Reuter, S. Dillinger, Supramolecular inorganic chemistry: small guests in small and large hosts, Angew. Chem. Int. Ed. Engl. 34 (1995) 2328-2361.

[5] P.V. Braun, P. Osenar, V. Tohver, S.B. Kennedy, S.I. Stupp, Nanostructure templating in inorganic solids with organic lyotropic liquid crystals, J. Am.Chem. Soc. 121 (1999) 7302-7309.

[6] M.-C. Daniel, D. Astruc, Gold nanoparticles: assembly, supramolecular chemistry, quantum-size-related properties, and applications toward biology, catalysis, and nanotechnology, Chem. Rev. 104 (2004) 293-346.

[7] Y. Li, Y. Yu, L. Wu, J. Zhi, Processable polyaniline/titanianano composites with good photocatalytic and conductivity properties prepared via peroxo-titanium complex catalyzed emulsion polymerization approach, Appl. Surf. Sci. 273 (2013) 135-143.

[8] E. T. Michalson, J. Szmuszkovicz, Medicinal agents incorporating the 1,2-diamine functionality, Progress in drug research, 33 (1989)135-149.

[9] V. Murugesan, M. Saravanabhavan, M. Sekar, Synthesis, spectral, structural characterization and biological investigation of $\mathrm{m}$-Xylylenediaminium bis(ptoluenesulfonate) monohydrate, J. Photochem. Photobiol B, 148 (2015) 358-365. 
[10] R. Kefi, M. Zeller, C. Ben Nasr, Synthesis and Crystal Structure of Bis[3(ammoniomethyl)pyridinium]-hexachloridocadmate Dihydrate, X-ray Structure Analysis Online, 30 (2014) 1-2.

[11] F.F. Jian, P. S. Zhao, Q. X. Wang, Y. Li, One-dimensional Cd metal string complex: Synthesis, structural and thermal properties of $\left[(\mathrm{HPy})_{3}\left(\mathrm{Cd}_{3} \mathrm{Cl}_{9}\right)\right]_{\infty}$, Inorg. Chim. Acta, 359 (2006) 1473-1477.

[12] C. K. Xia, Q. Z. Zhang, S. M. Chen, X. He, C. Z. Lu, Bis[2-(3pyridinio)benzimidazolium] di-[mu]-chloro-bis-[trichloro-cadmium(II)], Acta Cryst.C, 61 (2005) m203-m205.

[13] Bruker, APEX2, SAINT and SADABS, Bruker AXS Inc., Madison, Wisconsin, USA, 2006.

[14] G.M. Sheldrick, Crystal structure refinement with SHELXL, Acta Cryst. C71 (2015) 3-8.

[15] L.J. Farrugia, WinGX and ORTEP for Windows: an update, J. Appl. Cryst. 45 (2012) 849-854.

[16] R Dennington, T. Keith, J. Millam, GaussView, Version 5, Semichem. Inc, Shawnee Mission, KS, 2009.

[17] M.J. Frisch, G.W. Trucks, H.B. Schlegel, G.E. Scuseria, M.A. Robb, J.R. Cheeseman, G. Scalmani, V. Barone, B. Mennucci, G.A. Petersson, H. Nakatsuji, M. Caricato, X. Li, H.P. Hratchian, A.F. Izmaylov, J. Bloino, G. Zheng, J.L. Sonnenberg, M. Hada, M. Ehara, K. Toyota, R. Fukuda, J. Hasegawa, M. Ishida, T. Nakajima, Y. Honda, O. Kitao, H. Nakai, T. Vreven, J.A. Montgomery Jr., J.E. Peralta, F. Ogliaro, M. Bearpark, J.J. Heyd, E. Brothers, K.N. Kudin, V.N. Staroverov, R. Kobayashi, J. Normand, K. Raghavachari, A. Rendell, J.C. Burant, S.S. Iyengar, J. Tomasi, M. Cossi, N. Rega, J.M. Millam, M. Klene, J.E. Knox, J.B. Cross, V. Bakken, C. Adamo, J. Jaramillo, R. Gomperts, R.E. Stratmann, O. Yazyev, A.J. Austin, R. Cammi, C. Pomelli, J.W. Ochterski, R.L. Martin, K. Morokuma, V.G. Zakrzewski, G.A. Voth, P. Salvador, J.J. Dannenberg, S. Dapprich, A.D. Daniels, O. Farkas, J.B. Foresman, J.V. Ortiz, J. Cioslowski, D.J. Fox, Gaussian, 2009. Inc., Wallingford CT.

[18] A.D. Becke, Becke's three parameter hybrid method using the LYP correlation functional, J. Chem. Phys. 98 (1993) 5648-5652.

[19] C. Lee, W. Yang, R. G. Parr, Development of the Colle-Salvetticonelation energy formula into a functional of the electron density, Phys. Rev. 37 (1988) 785-789. 
[20] M.H. Jamroz, Vibrational Energy Distribution Analysis, VEDA 4, Computer Program, Poland, 2004.

[21] S.K. Wolff, D.J. Grimwood, J.J. McKinnon, D. Jayatilaka, M.A. Spackamn, CrystalExplorer 3.1, University of WestrenAustralia, Perth, 2013.

[22] T. Lu, F. Chen, Multiwfn: A multifunctional wavefunction analyzer, J. Comput. Chem. 33 (2012) 580-592.

[23] W. Humphrey, A. Dalke, K. Schulten, VMD—Visual molecular dynamics, J. Mol. Graph.14 (1996) 33-38 27-8.

[24] J-L Brédas, Mind the gap!, Materials Horizons 1 (2014) 17-19.

[25] R.G. Parr, R.G. Pearson, Absolute hardness: companion parameter to absolute electronegativity, J. Am. Chem. Soc. 105 (1983) 7512-7516.

[26] D. Romani, S. Tsuchiya, M. Yotsu-Yamashita, S.A.Brandán, Spectroscopic and structural investigation on intermediates species structurally associated to thetricyclic bisguanidine compound and to the toxic agent, saxitoxin, J. Mol.Struct. 1119 (2016) 25-38.

[27] D. Romani, S.A. Brandán, M.J. Márquez, M.B. Márquez, Structural, topological and vibrational properties of an isothiazole derivatives series with antiviral activities, J. Mol. Struct. 1100 (2015) 279-289.

[28] J.M. Yang, C.C. Chen, GEMDOCK: A Generic Evolutionary Method for Molecular Docking, Proteins Struct, Funct, Bioinf, 55 (2004) 288-304.

[29] E. Kose, A. Atac, F. Bardak, J. Mol. Struct. 10 (2018) 2-99.

[30] J. J. Irwin, T. Sterling, M.M. Mysinger, E.S. Bolstad, R.G. Coleman, ZINC: a free tool to discover chemistry for biology, J. Chem. Inf. Model, 527 (2012) 1757-1768.

[31] S. Haddad, A. Vij, R. D.Willett, Crystal structures of bis(4-dimethylaminopyridinium) tetrachlorocobaltate(II) and bis[1,3-di(ammoniummethyl)benzene] tetrachlorocobaltate(II), J. Chem. Crystallogr. 33 (2003) 245-251.

[32] R. Bala, R. P. Sharma, U. Sharma,V. Ferretti,The first X-ray structure of a hexa-ammine-cobalt(III) salt with two different complex chloro-cadmium anions: synthesis, characterization and crystal structure of $\left[\mathrm{Co}\left(\mathrm{NH}_{3}\right)_{6}\right]_{4}\left[\mathrm{CdCl}_{6}\right]\left[\mathrm{CdCl}_{4}(\mathrm{SCN})\left(\mathrm{H}_{2} \mathrm{O}\right)\right]_{2} \mathrm{Cl}_{2} \cdot 2 \mathrm{H}_{2} \mathrm{O}$, Acta Cryst.C, 62 (2006) m628m631.

[33] M. ElGlaoui, M. Zeller, E. Jeanneau, C. Ben Nasr, Bis(1-benzyl-piperazine-1,4-diium) hexa-chloridocadmate(II) dihydrate, Acta Cryst.E, 66 (2010) m895. 
[34] W. H. Baur, The geometry of polyhedral distortions. Predictive relationships for the phosphate group, Acta. Cryst B, 30 (1974) 1195-1215.

[35] H. Cheng, H. Li, (m-Phenylenedimethylene)diammonium dichloride, Acta Cryst E, 64 (2008) o2060.

[36] S. Gatfaoui, H. Dhaouadi, T. Roisnel, M. Rzaigui, H. Marouani, mXylylenediaminium dinitrate, Acta Cryst E, 70 (2014) o398-o399.

[37] S. Haddad, R. D. Willett, Dimeric Cu(I) Bromide Species Consisting of Two EdgeShared Tetrahedra: Crystal Structure of $\left(\mathrm{C}_{8} \mathrm{H}_{14} \mathrm{~N}_{2}\right)_{2} \mathrm{Cu}_{2} \mathrm{Br}_{6}$, Inorg. Chem. 40 (2001) 809-811

[38] J.J. McKinnon, A.S. Mitchell, M.A. Spackman, Hirshfeld surfaces: a new tool for visualising and exploring molecular crystals, Chem. A Eur. 4 (1998) 2136.

[39] M.A. Spackman, J.J. McKinnon, Fingerprinting intermolecular interactions in molecular crystals, CrystEngComm.4 (2002) 378.

[40] S.K. Seth, G.C. Maity, T. Kar, Structural elucidation, Hirshfeld surface analysis and quantum mechanical study of para-nitrobenzylidenemethylarjunolate, J. Mol. Struct. 1000 (2011) 120-126.

[41] J.L. Wardell, M.M. Jotani, E.R.T. Tieking, Two dialkylammonium salts of 2-amino-4nitrobenzoic acid: crystal structures and Hirshfeld surface analysis, Acta Cryst. E72 (2016) 1691-1699.

[42] M. H. Jamroz, Vibrational Energy Distribution Analysis, VEDA 4, Computer Program, Poland, 2004.

[43] S. Soudani, E. Jeanneau, C. Jelsch, F. Lefebvre, C. Ben Nasr, A hirshfeld surface analysis, crystal structure and physicochemical characterization of 1ethylpiperazinium trichlorocadmate(II), Solid State Sciences, 75 (2016) 49-55.

[44] L.M. Yang, Y. Liu, L.M. Man, J.R. Zhou, X.P. Liu, C.L. Ni, Crystal structure, vibrational spectra, optical properties and density functional theoretical approach of $\left[\mathrm{Bz}-4-\mathrm{NH}_{2} \mathrm{Py}\right]_{4}\left[\mathrm{CdCl}_{4}\right]_{2} \cdot \mathrm{H}_{2} \mathrm{O}, \mathrm{Vib}$. Spectrosc, 93 (2017) 23-28.

[45] A. Guesmi, T. Roisnel, H. Marouani, Featuring non-covalent interactions in mxylylenediaminium bis(perchlorate) monohydrate: Synthesis, characterization and Hirshfeld surface analysis, J. Mol. Struct. 1194 (2019) 66-72.

[46] R.F.W. Bader, Atoms in Molecules, A Quantum Theory, Oxford University Press, Oxford, 1990, ISBN 0198558651.

[47] S. Gatfaoui, N. Issaoui, S.A. Brandán, T. Roisnel, H. Marouani, Synthesis and characterization of p-xylylenediaminium bis(nitrate). Effects of the coordination 
modes of nitrate groups on their structural and vibrational properties, J. Mol. Struct.1151 (2018) 152-168.

[48] S. Trabelsi, N. Issaoui, S.A. Brandán, F. Bardak, T. Roisnel, A. Atac, H. Marouani, Synthesis and physic-chemical properties of a novel chromate compound with potential biological applications, bis(2-phenylethylammonium) chromate(VI), J. Mol. Struct. 1185 (2019) 168-182.

[49] M. Tahenti, S. Gatfaoui, N. Issaoui, T. Roisnel, H. Marouani, A tetrachlorocobaltate(II) salt with 2-amino-5-picolinium: Synthesis, theoretical and experimental characterization, J. Mol. Struct. 1207 (2020) 127781.

[50] U. Koch, P. Popelier, Characterization of C-H-O Hydrogen Bonds on the Basis of the Charge Density, J. Phys. Chem. Soc. A99 (1995) 9747.

[51] I. Rozas, I. Alkorta, J. Elguero, Behavior of Ylides Containing N, O, and C Atoms as Hydrogen Bond Acceptors, J. Am. Chem. Soc. 122 (2000) 11154-11161.

[52] E.R. Johnson, S. Keinan, P. Mori-Sánchez, J. Contreras-García, A.J. Cohen, W. Yang, J. Am. Chem. Soc. 132 (2010) 6498-6506.

[53] J. Contreras-Garcia, W. Yang, E.R. Johnson, Analysis of hydrogen-bond interaction potentials from the electron density: integration of non covalent interaction regions, $\mathrm{J}$. Phys. Chem. A 115 (2011) 12983-12990.

[54] G. Saleh, C. Gatti, L. Lo Presti, J. Contreras-Garcia, Revealing non-covalent interactions in molecular crystal through their experimental electron densities. Chem. Eur. J. 18 (2012) 15523-15536.

[55] J. Tauc, Optical properties and electronic structure of amorphous $\mathrm{Ge}$ and $\mathrm{Si}$, Mater. Res. Bul. 3 (1968) 37-46.

[56] R. Thirumurugan, B. Babu, K. Anitha and J. Chandrasekaran, Investigation on growth, structure and characterization of succinate salt of 8-hydroxyquinoline: An organic NLO crystal, Spectrochim. Acta Part A. 140 (2015) 44-53.

[57] Z. L. Wang, L. H.Wei, L. Y. Jin, J. P. Wang, Chin. J. Struct. Chem. 26 (2007) 1423.

[58] R.G. Parr, P.K. Chattaraj, Principle of maximum hardness, J. Am. Chem. Soc. 113 (1991) 1854-1855.

[59] R.G. Parr, R.G. Pearson, Absolute hardness: companion parameter to absolute electronegativity, J. Am. Chem. Soc. 105 (1983) 7512-7516. 
[60] R.S. Mulliken, A new electro affinity scale; together with data on valence states and on valence ionization potentials and electron affinities, J. Chem. Phys. 2 (1934) 782794.

[61] R.G. Parr, L. von Szentp_aly, S. Liu, Electrophilicity index, J. Am. Chem. Soc. 121 (1999) 1922-1924.

[62] J. Kausteklis, V. Aleksa, M. A. Iramain, S. A.Brandàn, Cation-anion interactions in 1buthyl-3-methyl imidazolium nitrate ionic liquid and their effect on their structural and vibrational properties, J. Mol. Struct. 1164 (2018) 1-14.

[63] M. Salihovic, S. Huseinovic, S. Spirtovic-Halilovic, A. Osmanovic, A. Dedic, Z. Asimovic, D. Zavrsnik, DFT study and biological activity of some methylxanthines, Bull. Chem. TechnolBosHerzeg 42 (2014) 31-36.

[64] W. Rui-Feng, Z. Tong-Lai, Q. Xiao-Jing, Z. Jian-Guo, Y. Li, Y. Wei, Synthesis and crystal structure of 7-nitro-5-sulfo-napthalene-1,4-dicarboxylate acid, Chinese J. Struct. Chem. 25 (2006) 849-853.

[65] O. Noureddine, S. Gatfaoui, S. A. Brandán, H. Marouani, N. Issaoui, Structural, docking and spectroscopic studies of a new piperazine derivative, 1-Phenylpiperazine1,4-diium-bis (hydrogen sulfate), J. Mol. Struct. 1202 (2020) 1-23.

[66] S. Gatfaoui, N. Issaoui, A. Mezni, F. Bardak, T. Roisnel, A. Atac, H. Marouani, Synthesis, structural and spectroscopic features, and investigation of bioactive nature of a novel organic-inorganic hybrid material 1H-1,2,4-triazole-4-iumtrioxonitrate, J. Mol. Struct. 1150 (2017) 242-257.

[67] W. R. Zhuang, Y. Wang, P.F. Cui, L. Xing, J. Lee, D. Kim, HL. Jiang, Y.K. Oh, Applications of $\pi-\pi$ stacking interactions in the design of drug-delivery systems, Journal of controlled release 294 (2019) 311-326. 


\section{Table captions}

Table 1. Crystal data and experimental parameters used for the intensity data collection strategy and final results of the structure determination.

Table 2. Principal intermolecular distances $(\AA)$ and bond angles $\left(^{\circ}\right)$ in $\left(\mathrm{C}_{8} \mathrm{H}_{14} \mathrm{~N}_{2}\right)_{2} \mathrm{CdCl}_{6}$ by $\mathrm{X}$-ray data (with estimated standard deviation in parentheses) and by theoretical calculations.

Table 3. Hydrogen-bonds geometry $\left(\AA{ }^{\circ}\right)$ of $\mathrm{MXDCdCl}_{6}$.

Table 4. Observed and calculated wavenumbers $\left(\mathrm{cm}^{-1}\right)$ and assignments for $\mathrm{MXDCdCl}_{6}$ molecule.

Table 5. Molecular Docking Results of binding energies in $\mathrm{kcal} \mathrm{mol}^{-1}$ via iGEMDOCK program. 
Table 1. Crystal data and experimental parameters used for the intensity data collection strategy and final results of the structure determination.

\begin{tabular}{|c|c|}
\hline Temperature & $150 \mathrm{~K}$ \\
\hline Empirical formula & $2\left(\mathrm{C}_{8} \mathrm{H}_{14} \mathrm{~N}_{2}\right) \mathrm{CdCl}_{6}$ \\
\hline Formula weight $\left(\mathrm{g} \mathrm{mol}^{-1}\right)$ & 601.52 \\
\hline Crystal system & Triclinic \\
\hline Space group & $\mathrm{P} \overline{1}$ \\
\hline $\mathrm{a}$ & $7.5482(8) \AA$ \\
\hline b & $8.495(1) \AA$ \\
\hline $\mathrm{c}$ & $10.4656(12) \AA$ \\
\hline$\alpha$ & $101.649(3)^{\circ}$ \\
\hline$\beta$ & $100.006(3)^{\circ}$ \\
\hline$\gamma$ & $112.971(3)^{\circ}$ \\
\hline $\mathrm{Z}$ & 1 \\
\hline V & $580.92(11) \AA^{3}$ \\
\hline $\mathrm{F}(000)$ & 302 \\
\hline$\mu(\mathrm{Mo} \mathrm{K} \alpha)$ & $1.64 \mathrm{~mm}^{-1}$ \\
\hline Index ranges & $-9 \leq \mathrm{h} \leq 9,-11 \leq \mathrm{k} \leq 11,-13 \leq 1 \leq 13$ \\
\hline Reflections collected & 13112 \\
\hline Independent reflections & 2661 \\
\hline Reflections with $\mathrm{I}>2 \sigma(\mathrm{I})$ & 2630 \\
\hline $\mathrm{R}_{\text {int }}$ & 0.025 \\
\hline$(\sin \theta / \lambda)_{\max }\left(\AA^{-1}\right)$ & 0.649 \\
\hline Absorption correction: multi-scan & $\mathrm{T}_{\min }=0.562, \mathrm{~T}_{\max }=0.653$ \\
\hline Refined parameters & 149 \\
\hline $\mathrm{R}\left[\mathrm{F}^{2}>2 \sigma\left(\mathrm{F}^{2}\right)\right]$ & 0.016 \\
\hline $\mathrm{wR}\left(\mathrm{F}^{2}\right)$ & 0.045 \\
\hline Goodness of fit & 1.22 \\
\hline$\Delta \rho_{\max }=0.41 \mathrm{e} \AA^{-3}$ & $\Delta \rho_{\min }=-0.45$ e $\AA^{-3}$ \\
\hline
\end{tabular}


Table 2. Principal intermolecular distances $(\AA)$ and bond angles $\left(^{\circ}\right)$ in $\left(\mathrm{C}_{8} \mathrm{H}_{14} \mathrm{~N}_{2}\right)_{2} \mathrm{CdCl}_{6}$ by $\mathrm{X}$-ray data (with estimated standard deviation in parentheses) and by theoretical calculations.

\begin{tabular}{|c|c|c|c|c|c|}
\hline \multicolumn{3}{|c|}{ Bond length $(\AA)$} & \multicolumn{3}{|l|}{ Bond angles $\left({ }^{\circ}\right)$} \\
\hline & $\begin{array}{l}\text { Calculated } \\
\text { B3LYP } \\
6-311++G(d, p)\end{array}$ & X-Ray & & $\begin{array}{l}\text { Calculated } \\
\text { B3LYP } \\
6-311++G(d, p)\end{array}$ & X-Ray \\
\hline \multicolumn{3}{|l|}{ Inorganic } & \multicolumn{3}{|c|}{8} \\
\hline $\mathrm{Cd} 1-\mathrm{Cl} 2$ & 2.7717 & $2.6449(4)$ & $\mathrm{Cl} 2-\mathrm{Cd} 1-\mathrm{Cl} 3$ & 88.8229 & $91.324(10)$ \\
\hline $\mathrm{Cd} 1-\mathrm{Cl} 3$ & 2.8012 & $2.5849(4)$ & $\mathrm{Cl} 2-\mathrm{Cd} 1-\mathrm{Cl} 4$ & 91.4463 & $90.183(14)$ \\
\hline $\mathrm{Cd} 1-\mathrm{Cl} 4$ & 2.7881 & $2.7177(4)$ & $\mathrm{Cl} 2-\mathrm{Cd} 1-\mathrm{Cl} 6$ & 91.1771 & $88.676(10)$ \\
\hline $\mathrm{Cd} 1-\mathrm{Cl} 5$ & 2.7717 & $2.6449(4)$ & $\mathrm{Cl} 2-\mathrm{Cd} 1-\mathrm{Cl} 7$ & 88.5537 & $89.817(14)$ \\
\hline $\mathrm{Cd} 1-\mathrm{Cl} 6$ & 2.8012 & $2.5849(4)$ & $\mathrm{Cl} 3-\mathrm{Cd} 1-\mathrm{Cl} 4$ & 90.6138 & $92.087(11)$ \\
\hline \multirow[t]{7}{*}{$\mathrm{Cd} 1-\mathrm{Cl} 7$} & 2.7881 & $2.7177(4)$ & $\mathrm{Cl} 3-\mathrm{Cd} 1-\mathrm{Cl} 5$ & 91.1771 & $88.676(10)$ \\
\hline & & & $\mathrm{Cl} 3-\mathrm{Cd} 1-\mathrm{Cl} 7$ & 89.3862 & $87.913(11)$ \\
\hline & & & $\mathrm{Cl} 4-\mathrm{Cd} 1-\mathrm{Cl} 5$ & 88.5537 & $89.817(14)$ \\
\hline & & & $\mathrm{Cl} 4-\mathrm{Cd} 1-\mathrm{Cl} 6$ & 89.3862 & $87.913(11)$ \\
\hline & & & $\mathrm{Cl} 5-\mathrm{Cd} 1-\mathrm{Cl} 6$ & 88.8229 & $91.324(10)$ \\
\hline & & & $\mathrm{Cl} 5-\mathrm{Cd} 1-\mathrm{Cl} 7$ & 91.4463 & $90.183(14)$ \\
\hline & & & Cl6- Cd1-Cl7 & 90.6138 & $92.087(11)$ \\
\hline \multicolumn{6}{|l|}{ Organic } \\
\hline $\mathrm{N} 8-\mathrm{C} 23$ & 1.509 & 1.4907 (19) & C12-C10-C16 & 119.4547 & $119.49(13)$ \\
\hline N9-C18 & 1.5295 & $1.4943(18)$ & C12-C10-C18 & 120.6014 & $120.11(14)$ \\
\hline $\mathrm{C} 10-\mathrm{C} 12$ & 1.4143 & $1.396(2)$ & C16-C10-C18 & 119.9431 & 120.39 (14) \\
\hline $\mathrm{C} 10-\mathrm{C} 16$ & 1.4074 & $1.393(2)$ & C14-C11-C16 & 119.0631 & $119.41(14)$ \\
\hline C10-C18 & 1.514 & $1.505(2)$ & $\mathrm{C} 14-\mathrm{C} 11-\mathrm{C} 23$ & 120.2001 & $120.79(13)$ \\
\hline C11-C14 & 1.4094 & $1.392(2)$ & C16-C11-C23 & 120.7226 & $119.78(13)$ \\
\hline C11-C16 & 1.4134 & $1.396(2)$ & $\mathrm{C} 10-\mathrm{C} 12-\mathrm{C} 21$ & 120.0256 & $119.76(14)$ \\
\hline $\mathrm{C} 11-\mathrm{C} 23$ & 1.5179 & 1.5089 (19) & C11-C14-C21 & 120.3842 & $119.96(14)$ \\
\hline $\mathrm{C} 12-\mathrm{C} 21$ & 1.4048 & $1.386(2)$ & C10-C16-C11 & 120.9009 & $120.73(14)$ \\
\hline \multirow[t]{3}{*}{ C14-C21 } & 1.41 & $1.394(2)$ & N9-C18-C10 & 111.6645 & $111.61(11)$ \\
\hline & & & C12-C21-C14 & 120.163 & $120.62(14)$ \\
\hline & & & N8-C23-C11 & 112.2668 & $112.22(12)$ \\
\hline
\end{tabular}


Table 3. Hydrogen-bonds geometry $\left(\AA{ }^{\circ}{ }^{\circ}\right)$ of $\mathrm{MXDCdCl}_{6}$.

\begin{tabular}{|c|c|c|c|c|}
\hline $\mathbf{D}-\mathbf{H} \cdot \cdots \mathbf{A}$ & $\mathbf{D}-\mathbf{H}(\AA)$ & $\mathbf{H} \cdot \cdots \mathbf{A}(\AA)$ & $\mathbf{D} \cdots \mathbf{A}(\AA)$ & $\mathbf{D}-\mathbf{H} \cdot \cdots \mathbf{A}\left(\left(^{\circ}\right)\right.$ \\
\hline $\mathrm{N} 1-\mathrm{H} 1 \mathrm{N1} \cdots \mathrm{Cl3}^{\mathrm{i}}$ & $0.92(3)$ & $2.34(3)$ & $3.2427(14)$ & $167(2)$ \\
\hline $\mathrm{N} 1-\mathrm{H} 2 \mathrm{~N} 1 \cdots \mathrm{Cl1}^{\mathrm{ii}}$ & $0.83(2)$ & $2.55(2)$ & $3.1658(14)$ & $131.7(19)$ \\
\hline $\mathrm{N} 1-\mathrm{H} 2 \mathrm{~N} 1 \cdots \mathrm{Cl}^{\mathrm{iii}}$ & $0.83(2)$ & $2.80(2)$ & $3.4410(13)$ & $135.0(19)$ \\
\hline $\mathrm{N} 1-\mathrm{H} 3 \mathrm{~N} 1 \cdots \mathrm{Cl} 2$ & $0.91(2)$ & $2.38(2)$ & $3.2147(14)$ & $152.5(19)$ \\
\hline N1-H3N1‥Cl1 & $0.91(2)$ & $2.86(2)$ & $3.3018(13)$ & $111.1(17)$ \\
\hline $\mathrm{N} 2-\mathrm{H} 1 \mathrm{~N} 2 \cdots \mathrm{Cl} 2^{\mathrm{iv}}$ & $0.81(3)$ & $2.49(3)$ & $3.2229(14)$ & $152(2)$ \\
\hline $\mathrm{N} 2-\mathrm{H} 1 \mathrm{~N} 2 \cdots \mathrm{Cl1}^{\mathrm{v}}$ & $0.81(3)$ & $2.82(3)$ & $3.2936(14)$ & $119(2)$ \\
\hline $\mathrm{N} 2-\mathrm{H} 1 \mathrm{~N} 2 \cdots \mathrm{Cl3}^{\mathrm{v}}$ & $0.81(3)$ & $3.05(3)$ & $3.4049(14)$ & $109(2)$ \\
\hline $\mathrm{N} 2-\mathrm{H} 2 \mathrm{~N} 2 \cdots \mathrm{Cl} 1^{\mathrm{vi}}$ & $0.89(2)$ & $2.40(2)$ & $3.2176(14)$ & $153(2)$ \\
\hline $\mathrm{N} 2-\mathrm{H} 3 \mathrm{~N} 2 \cdots \mathrm{Cl}^{\mathrm{vii}}$ & $0.91(2)$ & $2.49(2)$ & $3.2431(14)$ & $140.8(19)$ \\
\hline $\mathrm{C} 3-\mathrm{H} 3 \cdots \mathrm{Cl} 2$ & 0.93 & 2.80 & $3.5631(15)$ & 140 \\
\hline $\mathrm{C} 5-\mathrm{H} 5 \cdots \mathrm{Cl1}^{\mathrm{vi}}$ & 0.93 & 2.78 & $3.6421(15)$ & 155 \\
\hline
\end{tabular}

Symmetry codes: $x-1, y, z$; (ii) $-x+1,-y,-z$; (iii) $-x+2,-y,-z$; (iv) $-x+2,-y,-z+1$; (v) $x, y, z+1$; (vi) $-x+2,-y+1,-z+1$; (vii) $-x+3,-y+1,-z+1$. 
Table 4. Observed and calculated wavenumbers $\left(\mathrm{cm}^{-1}\right)$ and assignments for $\mathrm{MXDCdCl}_{6}$ molecule.

\begin{tabular}{|c|c|c|c|c|}
\hline \multicolumn{5}{|c|}{ Calculated frequencies } \\
\hline $\begin{array}{l}\text { Experimental } \\
\text { IR }\end{array}$ & Unscaled & Scaled & $\mathrm{I}^{\mathrm{i}}$ & Vibrational assignments (\% PED) \\
\hline 3439 & 3606 & 3455 & 59.98 & vNH (99) \\
\hline \multirow[t]{7}{*}{3439} & 3593 & 3442 & 65.72 & vNH (99) \\
\hline & 3263 & 3126 & 23.46 & vCH (95) \\
\hline & 3234 & 3098 & 20.51 & vCH (99) \\
\hline & 3225 & 3090 & 4.26 & vCH (95) \\
\hline & 3214 & 3079 & 25.28 & vCH (99) \\
\hline & 3196 & 3062 & 7.23 & vCH (99) \\
\hline & 3193 & 3059 & 11.69 & vCH (96) \\
\hline 3112 & 3144 & 3012 & 413.63 & vNH (88) \\
\hline 2730 & 3127 & 2995 & 7.02 & vCH (98) \\
\hline 2730 & 3121 & 2990 & 76.67 & ৩CH (91) \\
\hline 2559 & 3038 & 2910 & 758.87 & vNH (88) \\
\hline 2559 & 2943 & 2819 & 1075.71 & vNH (91) \\
\hline 2559 & 2800 & 2683 & 1050.56 & vNH (95) \\
\hline 1634 & 1735 & 1663 & 112.15 & $\beta \mathrm{HNH}(65)$ \\
\hline 1634 & 1731 & 1658 & 145.64 & $\beta \mathrm{HNH}(58)$ \\
\hline 1593 & 1711 & 1639 & 5.45 & vCC (37) \\
\hline 1593 & 1698 & 1669 & 52.04 & $\beta \mathrm{HNH}(57) \quad \delta \mathrm{HNHCl}(25)$ \\
\hline \multirow[t]{2}{*}{1593} & 1685 & 1656 & 1.39 & vCC (51) $\beta \mathrm{CCC}(12)$ \\
\hline & & & & $\beta \mathrm{HNH}(41) \quad \delta \mathrm{HNHCl}(17) \quad \delta \mathrm{CNHCl}$ \\
\hline 1593 & 1674 & 1645 & 199.95 & (13) \\
\hline 1593 & 1666 & 1638 & 40.97 & $\delta \mathrm{HNHCl}(13) \quad \beta \mathrm{HNH}(42)$ \\
\hline 1593 & 1640 & 1612 & 75.13 & $\delta \mathrm{HNHCl}(85)$ \\
\hline 1476 & 1561 & 1535 & 7.33 & $\beta \mathrm{HCC}(42) \beta C C C$ (10) \\
\hline 1476 & 1546 & 1520 & 18.16 & $\beta \mathrm{HCH}(76)$ \\
\hline 1476 & 1541 & 1515 & 13.68 & $\beta \mathrm{HCH}(75) \quad \delta \mathrm{HCCC}(14)$ \\
\hline \multirow[t]{3}{*}{1476} & 1511 & 1485 & 11.82 & vCC (45) $\beta \mathrm{HCC}(27)$ \\
\hline & 1451 & 1426 & 8.29 & $\delta \mathrm{HCCC}(36)$ \\
\hline & 1438 & 1414 & 9.89 & $\delta \mathrm{HCCC}(59)$ \\
\hline 1367 & 1405 & 1381 & 4.60 & $\beta \mathrm{HCC}(76)$ \\
\hline \multirow[t]{3}{*}{1367} & 1393 & 1369 & 2.20 & vCC (42) $\beta \mathrm{HCC}(15)$ \\
\hline & 1358 & 1335 & 5.48 & $\delta \mathrm{HCCC}(32)$ \\
\hline & 1345 & 1322 & 6.32 & ৩CC (10) $\delta \mathrm{HCCC}(28)$ \\
\hline 1300 & 1313 & 1290 & 11.59 & vCC (45) $\beta \mathrm{HCC}(11) \quad \beta C C C$ (10) \\
\hline 1300 & 1257 & 1235 & 7.78 & $\beta \mathrm{HCC}(43) \quad$ oCC (18) \\
\hline 1300 & 1233 & 1212 & 21.40 & $\beta \mathrm{HCC}(55)$ \\
\hline 1165 & 1205 & 1185 & 36.33 & $\delta \mathrm{HNHCl}(22) \quad \beta \mathrm{HNC}(18)$ \\
\hline 1165 & 1189 & 1169 & 19.41 & $\delta \mathrm{HNHCl}(29) \quad \beta \mathrm{HCC}(12)$ \\
\hline 1165 & 1176 & 1156 & 1.27 & $\beta \mathrm{HNC}(23) \quad \beta \mathrm{HCC}(19)$ \\
\hline \multirow[t]{2}{*}{1165} & 1162 & 1142 & 10.54 & $\beta \mathrm{HCC}(34) \quad \beta \mathrm{HNC}(15)$ \\
\hline & 1125 & 1106 & 16.93 & vCC (24) $\beta \mathrm{HCC}(21)$ \\
\hline
\end{tabular}




\begin{tabular}{|c|c|c|c|c|}
\hline \multicolumn{5}{|c|}{ Journal Pre-proof } \\
\hline 1095 & 1061 & 1043 & 4.87 & $\delta \mathrm{HCCC}(78)$ \\
\hline \multirow[t]{5}{*}{1095} & 1049 & 1031 & 4.38 & $\delta \mathrm{HCCC}(55) \quad \delta C C C C(11)$ \\
\hline & 1035 & 1018 & 0.83 & vNC (44) \\
\hline & 1032 & 1015 & 0.36 & vCC (10) vNC (12) $\beta C C C$ (44) \\
\hline & 1010 & 993 & 35.38 & vNC (72) \\
\hline & 986 & 969 & 2.74 & $\delta \mathrm{HCCC}(65)$ \\
\hline 907 & 958 & 942 & 11.21 & $\delta \mathrm{HCCC}(22) \quad$ vNC (11) \\
\hline 878 & 943 & 927 & 16.61 & $\delta \mathrm{HCCC}(30)$ \\
\hline 853 & 909 & 893 & 4.47 & $\beta \mathrm{HCC}(14) \quad v \mathrm{CC}(12) \quad \delta \mathrm{HCCC}(23)$ \\
\hline 807 & 849 & 835 & 36.08 & $\delta \mathrm{HCCC}(66)$ \\
\hline \multirow{2}{*}{701} & 758 & 745 & 42.47 & $\delta \mathrm{HCCC}(23) \quad \gamma \mathrm{CCCC}(14)$ \\
\hline & 739 & 726 & 6.18 & vCC (27) $\beta \mathrm{CCC}(30)$ \\
\hline 547 & 657 & 645 & 0.67 & $\gamma \operatorname{CCCC~(22)~} \beta C C N(23) \beta C C C ~(12)$ \\
\hline 547 & 586 & 576 & 2.33 & $\beta C C C(53)$ \\
\hline 547 & 531 & 522 & 1.19 & $\beta C C C$ (49) \\
\hline \multirow[t]{23}{*}{456} & 487 & 479 & 11.56 & $\delta \mathrm{HCCC}(13) \quad \gamma \mathrm{CCCC}(29)$ \\
\hline & 423 & 416 & 2.77 & $\beta C C C(54)$ \\
\hline & 405 & 398 & 6.18 & $\beta \mathrm{NHCl}(32) \quad \delta \mathrm{HNCC}(11)$ \\
\hline & 388 & 381 & 2.57 & $\beta C C C(47)$ \\
\hline & 378 & 371 & 36.31 & $\beta C C C$ (43) vClH (20) \\
\hline & 338 & 333 & 51.38 & $\delta \mathrm{CCCC}(16) \quad$ vClH (21) \\
\hline & 303 & 298 & 52.92 & $v \mathrm{ClH}(56) \quad \beta \mathrm{CCC}(11)$ \\
\hline & 290 & 285 & 30.32 & vClH (38) \\
\hline & 254 & 249 & 5.63 & $\beta C C C ~(33)$ \\
\hline & & & & $\delta \mathrm{CCCC}(17) \quad v \mathrm{ClH}(21) \quad \delta \mathrm{HNHCl}$ \\
\hline & 232 & 228 & 51.23 & $(14)$ \\
\hline & & & & vClH (21) $\delta \mathrm{HNHCl}(11) \quad \delta \mathrm{HNCC}$ \\
\hline & 217 & 213 & 52.63 & $(11)$ \\
\hline & 193 & 190 & 27.28 & $\mathrm{vCdCl}(65)$ \\
\hline & 171 & 168 & 46.13 & $v \mathrm{CdCl}(18) \quad \delta \mathrm{CNHCl}(15)$ \\
\hline & 151 & 148 & 3.96 & $\beta C C N(22) \quad \delta C C C N(15)$ \\
\hline & 138 & 136 & 4.19 & $\gamma \mathrm{CCCC}(16) \quad v \mathrm{ClH}(18) \quad \delta \mathrm{HNHCl}(21)$ \\
\hline & & & & $\beta \mathrm{NHCl}(14) \quad \delta \mathrm{CCCN}(14) \quad \delta \mathrm{HNCC}$ \\
\hline & 116 & 114 & 18.59 & $(13)$ \\
\hline & 109 & 107 & 12.27 & $\beta \mathrm{NHCl}(26)$ \\
\hline & & & & $\delta \mathrm{CCCN}(11) \delta \mathrm{HNCC}(12) \quad \delta \mathrm{HNCC}$ \\
\hline & 95 & 93 & 2.31 & $(13)$ \\
\hline & 74 & 73 & 1.64 & $\beta \mathrm{HClCd}(50) \quad \delta \mathrm{HNCC}(11)$ \\
\hline
\end{tabular}

$\mathrm{I}^{\mathrm{i}}$ : infraredintensity $\left(\mathrm{km} \cdot \mathrm{mol}^{-1}\right) . v, \beta, \delta$ and $\gamma$ denote stretching, in-planebending, torsion and out-of-plane bending modes, respectively.

PED: potential energy distribution data are taken fromVEDA4

Scaling factor: from 4000 to $1700 \mathrm{~cm}^{-1}$ are scaled with 0.983 and lower than $1700 \mathrm{~cm}^{-1}$ are scaled with 0.958 . 
Table 5. Molecular Docking Results of binding energies in $\mathrm{kcal} \mathrm{mol}^{-1}$ via iGEMDOCK program.

\begin{tabular}{c|cccc|c|c|c}
\hline Ligand & Bacteria & Total energy & VDW & H-bond & Electronic & AverConPair \\
\hline \multirow{5}{*}{} & $1 \mathrm{XK} 9$ & -92.702 & -92.534 & 0 & -0.168 & 26.130 \\
& $5 \mathrm{Y} 63$ & -92.407 & -91.626 & 0 & -0.781 & 25.000 \\
& $5 \mathrm{NV} 5$ & -89.613 & -89.957 & 0 & 0.344 & 26.478 \\
$\left(\mathrm{C}_{8} \mathrm{H}_{14} \mathrm{~N}_{2}\right)_{2} \mathrm{CdCl}_{6}$ & $3 \mathrm{KP3}$ & -89.093 & -88.873 & 0 & -0.220 & 22.391 \\
& $4 \mathrm{OYH}$ & -84.719 & -84.263 & 0 & -0.455 & 23.391 \\
& $6 \mathrm{G} 9 \mathrm{P}$ & -84.630 & -85.658 & 0 & 1.027 & 25.521 \\
& $2 \mathrm{~W} 7 \mathrm{Q}$ & -80.698 & -80.692 & 0 & -0.006 & 26.826 \\
& $5 \mathrm{O} 7$ & -72.670 & -72.670 & 0 & 0 & 20.087 \\
\hline
\end{tabular}




\section{Figure captions}

Fig. 1. ORTEP drawing of $\left(\mathrm{C}_{8} \mathrm{H}_{14} \mathrm{~N}_{2}\right)_{2}\left[\mathrm{CdCl}_{6}\right]$ with atom-labeling scheme. Displacement ellipsoids are drawn at the $30 \%$ probability level. (i) (-x, -y, -z). $\mathrm{H}$ atoms are represented as small spheres of arbitrary radii. Hydrogen bonds are denoted as dashed lines (a) and the optimized molecular structure (b).

Fig. 2. The packing of $\left(\mathrm{C}_{8} \mathrm{H}_{14} \mathrm{~N}_{2}\right)_{2}\left[\mathrm{CdCl}_{6}\right]$ viewed down the $a$-axis (a), and along the $b$-axis (b), $\mathrm{CdCl}_{6}$ is given in polyhedral representation. Hydrogen bonds are denoted as dashed lines. View highlighting intermolecular interactions between organic cations C-H... $\pi$ stacking (c).

Projection of a layer in the plane (a,b) showing the patterns of hydrogen bonding in the title compound. $\mathrm{H}$ atoms not involved in hydrogen bonding were omitted while carbon atoms were omitted for clarity of the projection along the c-axis (d).

Fig. 3. Hirshfeld surfaces mapped with $d_{\text {norm }}$. The surfaces are shown as transparent to highlight the visualization of the orientation and conformation of the functional groups in the crystal, hydrogen bonds are represented by dotted lines.

Fig. 4. 2D fingerprint plots of the main intercontacts showing percentage of various intermolecular contacts contributed to the Hirshfeld surface in the title compound. Surfaces to the side highlight the relevant surface patches associated with the specific contacts.

Fig. 5. Theoretical and experimental IR spectrum of $\mathrm{MXDCdCl}_{6}$.

Fig. 6. AIM molecular graph screening the different bond critical points (BCPs) of $\left(\mathrm{C}_{8} \mathrm{H}_{14} \mathrm{~N}_{2}\right)_{2} \mathrm{CdCl}_{6}$ calculated at DFT/LANL2DZ level. The BCPs are denoted as orange smaller balls.

Fig. 7. Graphical representation for the corresponding cation: bond critical points (small red spheres), ring critical points (small yellow spheres), cage critical points (small green spheres), bond paths (pink lines).

Fig. 8. Plots of the RDG versus the electron density $\rho$ multiplied by the sign of $\lambda_{2}$ (a) and color scaling of weak interactions (b) for the $\left(\mathrm{C}_{8} \mathrm{H}_{14} \mathrm{~N}_{2}\right)_{2} \mathrm{CdCl}_{6}$ compound. The surfaces are colored on a blue-green-red scale according to values of sign $\lambda_{2}$. Blue indicates strong attractive interactions and red indicates strong non-bonded overlap 
Fig. 9. Plots of the RDG versus the electron density $\rho$ multiplied by the sign of $\lambda_{2}$ (a) and color scaling of weak interactions (b) for the corresponding cation of $\mathrm{MXDCdCl}_{6}$. The surfaces are colored on a blue-green-red scale according to values of sign $\lambda_{2}$. Blue indicates strong attractive interactions and red indicates strong non-bonded overlap.

Fig. 10. Theoretical TD-DFT UV-Visible spectrum of the title compound at BLYP and B3LYP level.

Fig. 11. Solid-state UV-Vis spectrum (a) of $\left(\mathrm{C}_{8} \mathrm{H}_{14} \mathrm{~N}_{2}\right)_{2} \mathrm{CdCl}_{6}$ and the energy gap (b) according to the Tauc model.

Fig. 12. The frontier molecular orbitals of $\left(\mathrm{C}_{8} \mathrm{H}_{14} \mathrm{~N}_{2}\right)_{2} \mathrm{CdCl}_{6}$ molecule at DFT/LANL2DZ level.

Fig. 13. The best docked poses of $\left(\mathrm{C}_{8} \mathrm{H}_{14} \mathrm{~N}_{2}\right)_{2} \mathrm{CdCl}_{6}$ compound with eight bacteria: $1 \mathrm{XK} 9(\mathrm{a})$, 5Y63(b), 5NV5(c), 3KP3(d), 4OYH(e), 6G9P(f), 2W7Q(g), 5O77(h).

Fig. 14. Different types of interactions between $\left(\mathrm{C}_{8} \mathrm{H}_{14} \mathrm{~N}_{2}\right)_{2} \mathrm{CdCl}_{6}$ and $1 \mathrm{XK} 9$ bacteria. 
(a)

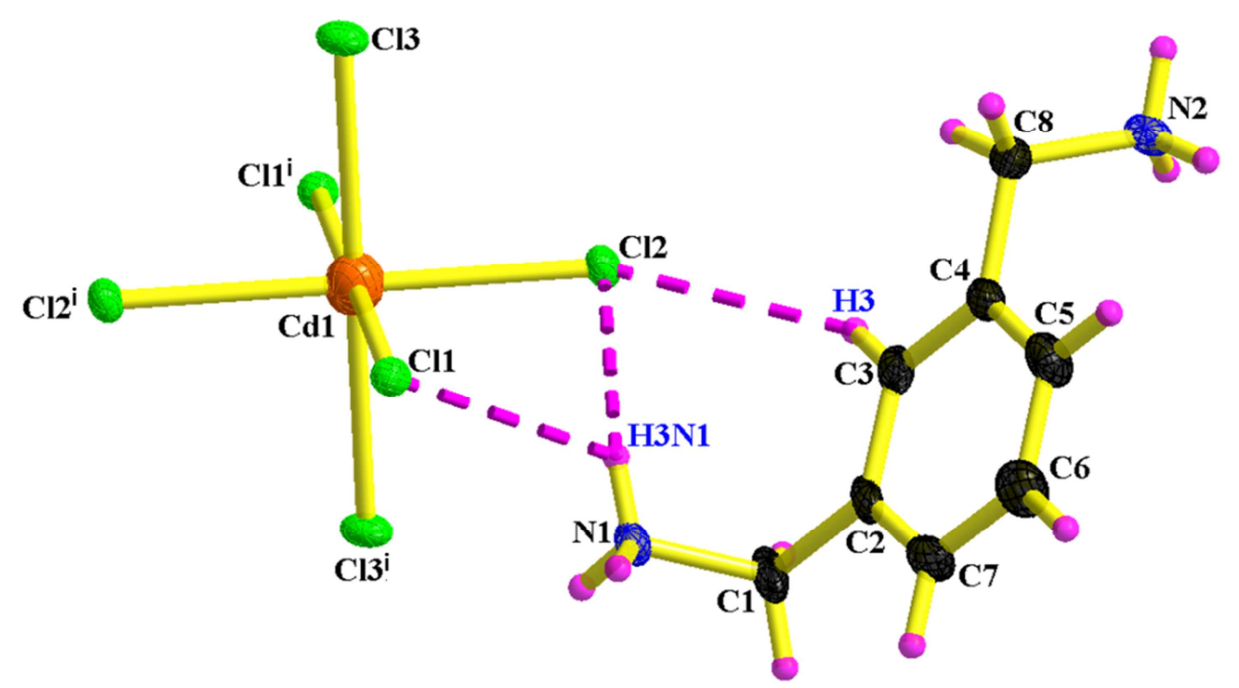

(b)

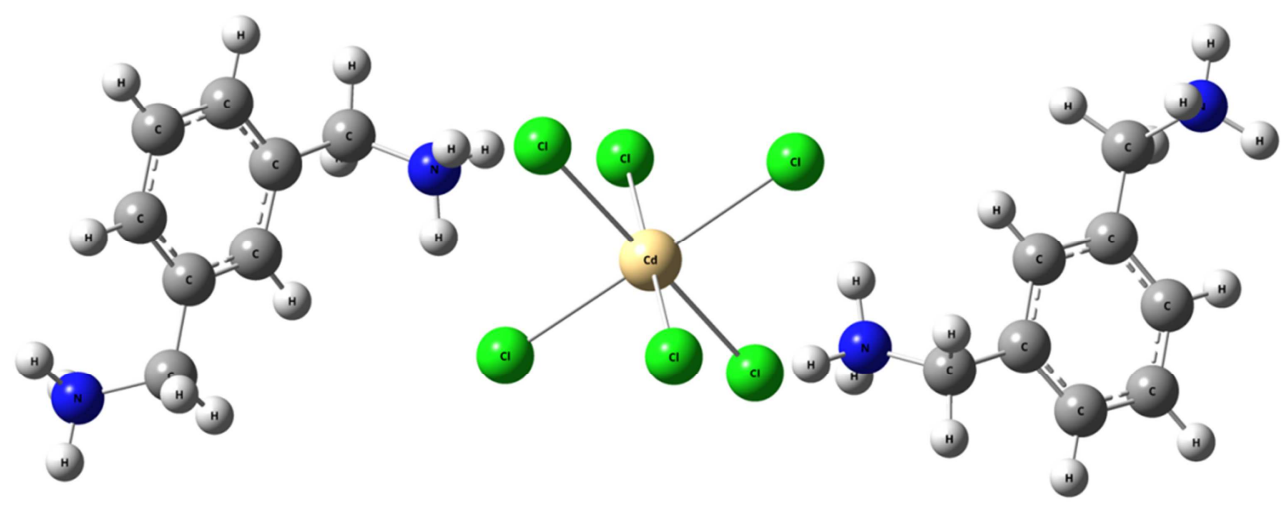

Fig. 1. ORTEP drawing of $\left(\mathrm{C}_{8} \mathrm{H}_{14} \mathrm{~N}_{2}\right)_{2}\left[\mathrm{CdCl}_{6}\right]$ with atom-labeling scheme. Displacement ellipsoids are drawn at the $30 \%$ probability level. (i) (-x, -y, -z). H atoms are represented as small spheres of arbitrary radii. Hydrogen bonds are denoted as dashed lines (a) and the optimized molecular structure (b). 
(a)

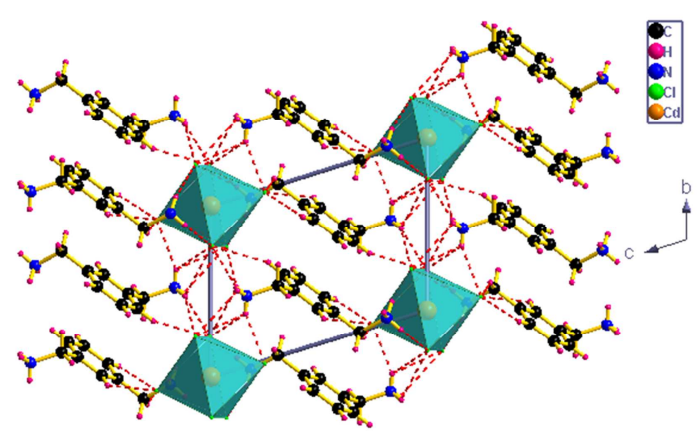

(c)

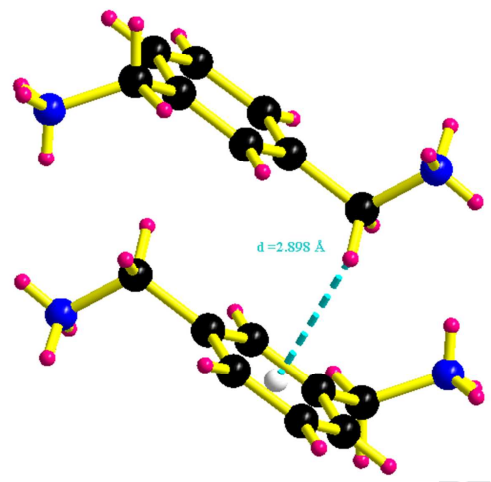

(b)

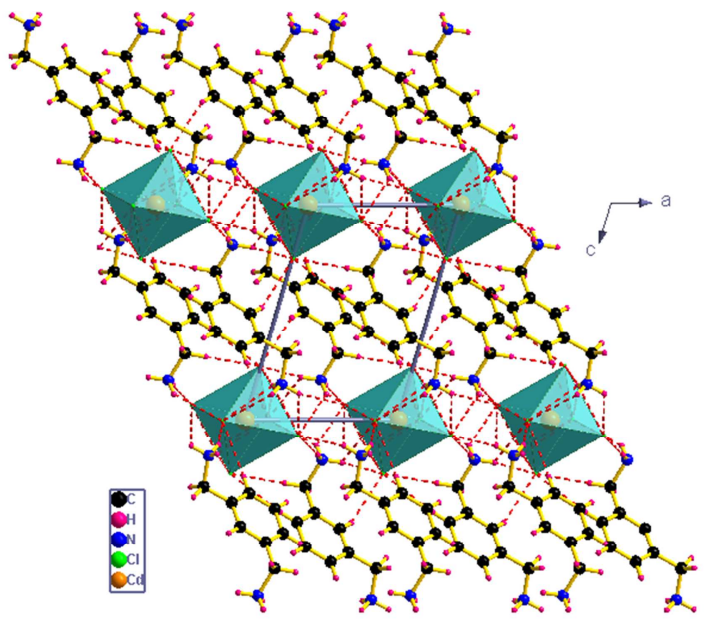

(d)

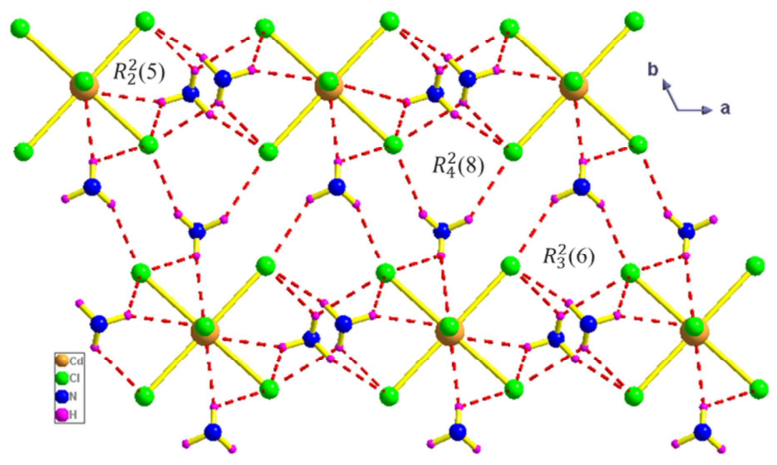

Fig. 2. The packing of $\left(\mathrm{C}_{8} \mathrm{H}_{14} \mathrm{~N}_{2}\right)_{2}\left[\mathrm{CdCl}_{6}\right]$ viewed down the $a$-axis (a), and along the $b$-axis (b), $\mathrm{CdCl}_{6}$ is given in polyhedral representation. Hydrogen bonds are denoted as dashed lines. View highlighting intermolecular interactions between organic cationsC-H... $\pi$ stacking(c). Projection of a layer in the plane (a,b) showing the patterns of hydrogen bonding in the title compound. $\mathrm{H}$ atoms not involved in hydrogen bonding were omitted while carbon atoms were omitted for clarity of the projection along the c-axis (d). 


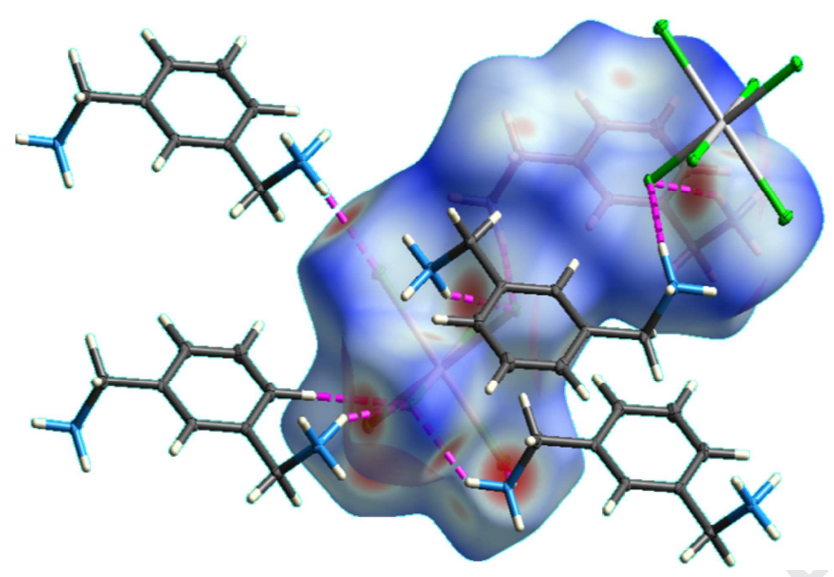

Fig. 3. Hirshfeld surfaces mapped with $d_{\text {norm. }}$. The surfaces are shown as transparent to highlight the visualization of the orientation and conformation of the functional groups in the crystal, hydrogen bonds are represented by dotted line 

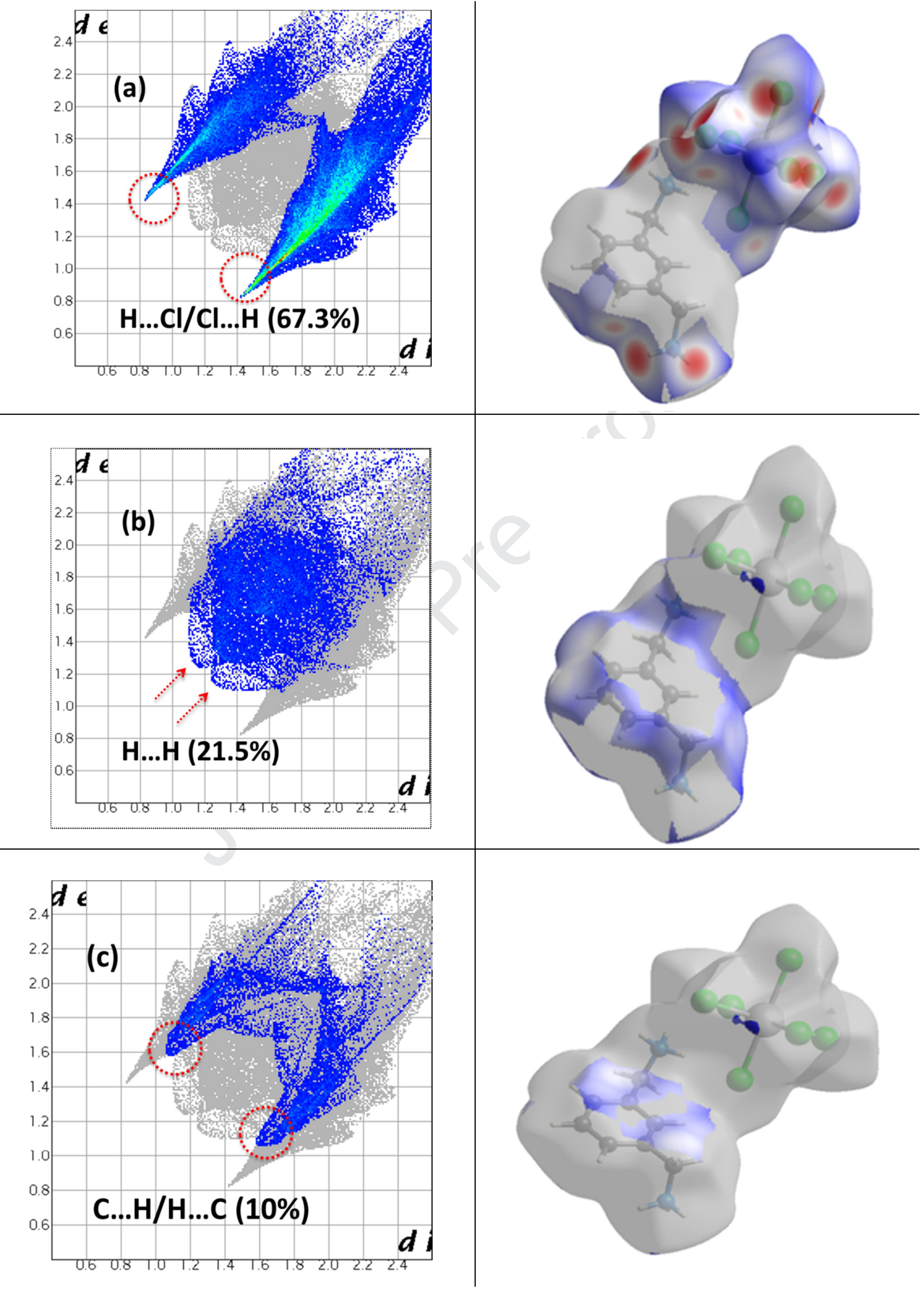

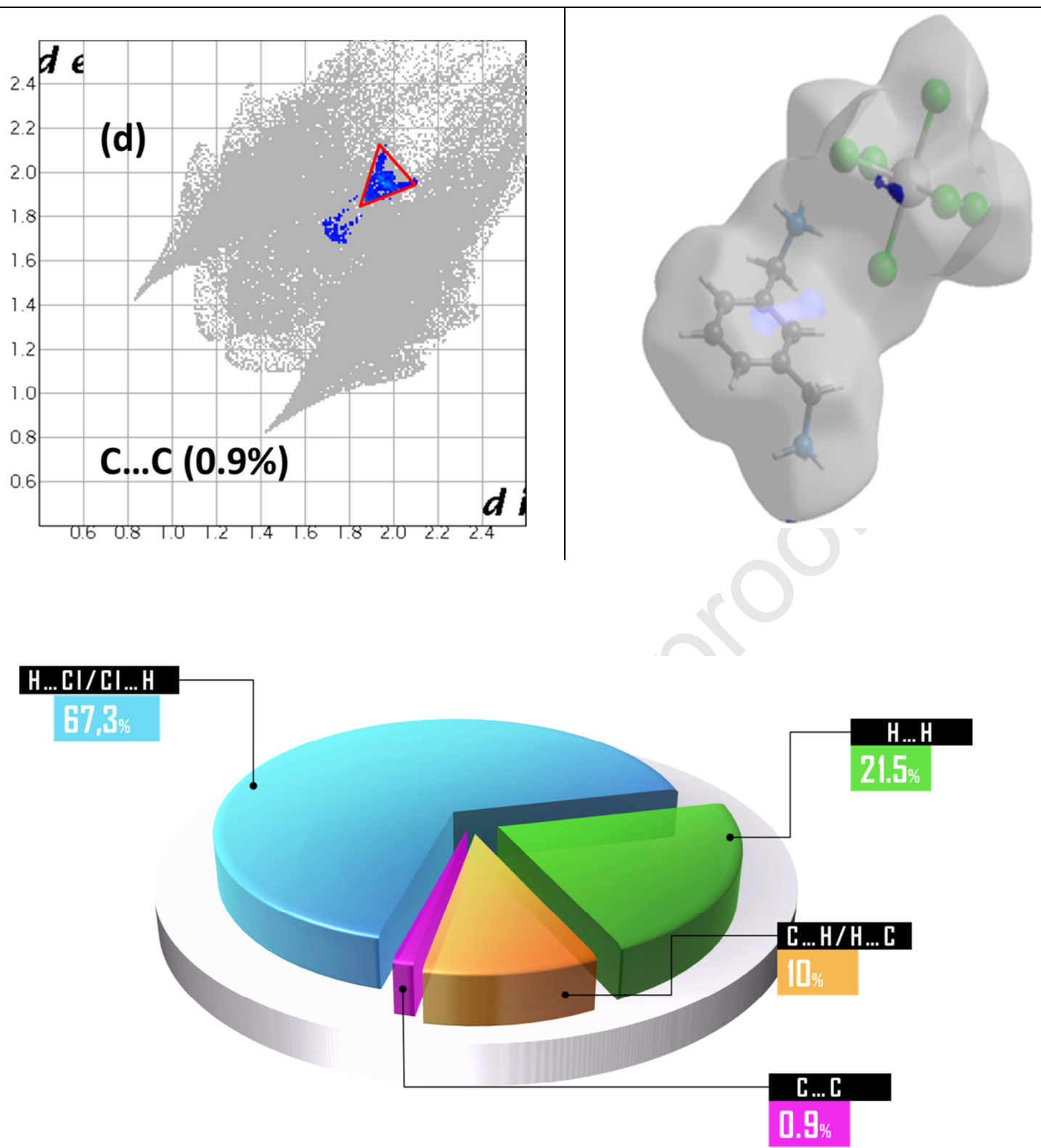

Fig. 4. 2D fingerprint plots of the main intercontacts showing percentage of various intermolecular contacts contributed to the Hirshfeld surface in the title compound. Surfaces to the side highlight the relevant surface patches associated with the specific contacts. 


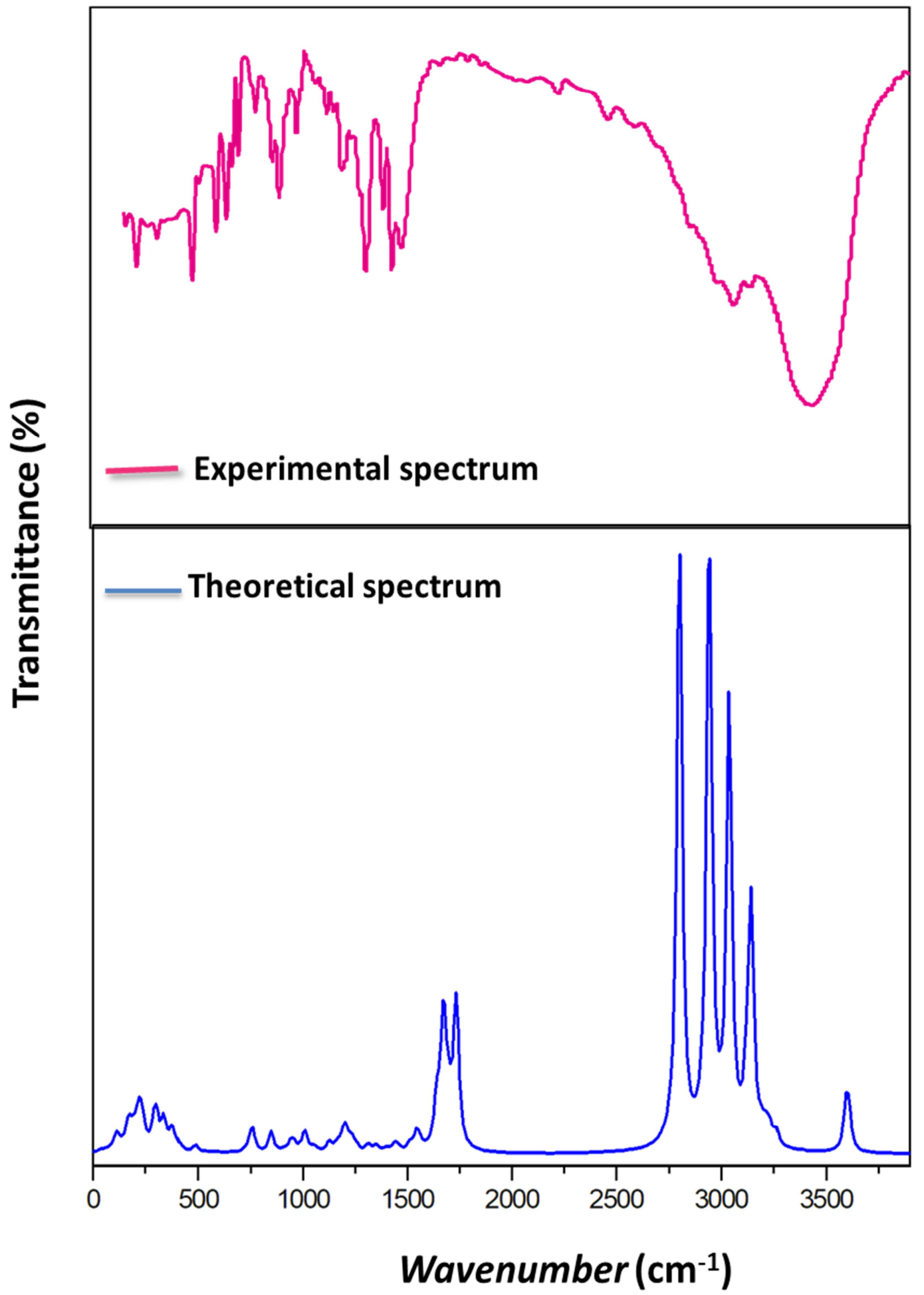

Fig.5. Theoretical and experimental IR spectrum of $\mathrm{MXDCdCl}_{6}$. 


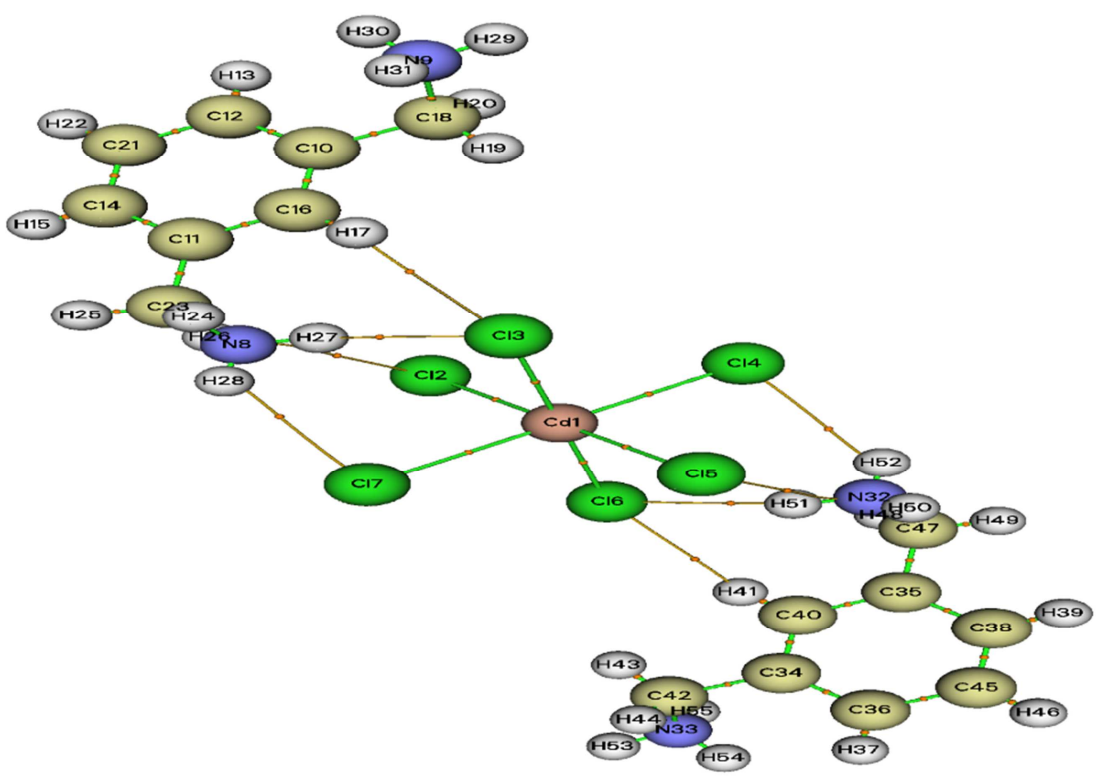

Fig. 6. AIM molecular graph screening the different bond critical points (BCPs) of $\left(\mathrm{C}_{8} \mathrm{H}_{14} \mathrm{~N}_{2}\right)_{2} \mathrm{CdCl}_{6}$ calculated with B3LYP/6-311++G(d,p) level. The BCPs are denoted as orange smaller balls.

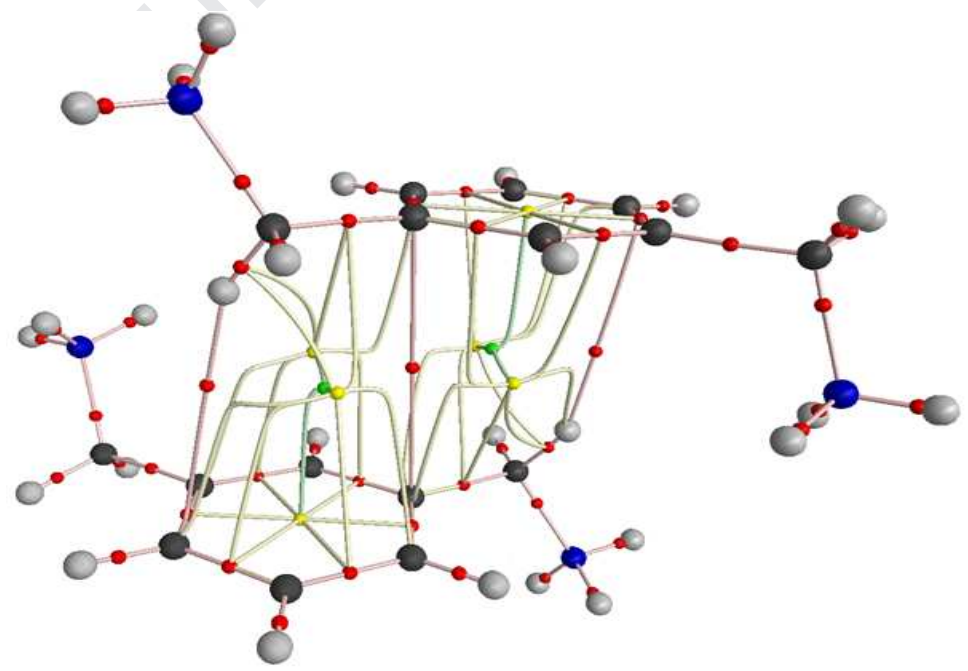

Fig. 7. Graphical representation for the corresponding cation: bond critical points (small red spheres), ring critical points (small yellow spheres), cage critical points (small green spheres), bond paths (pink lines). 
(a)

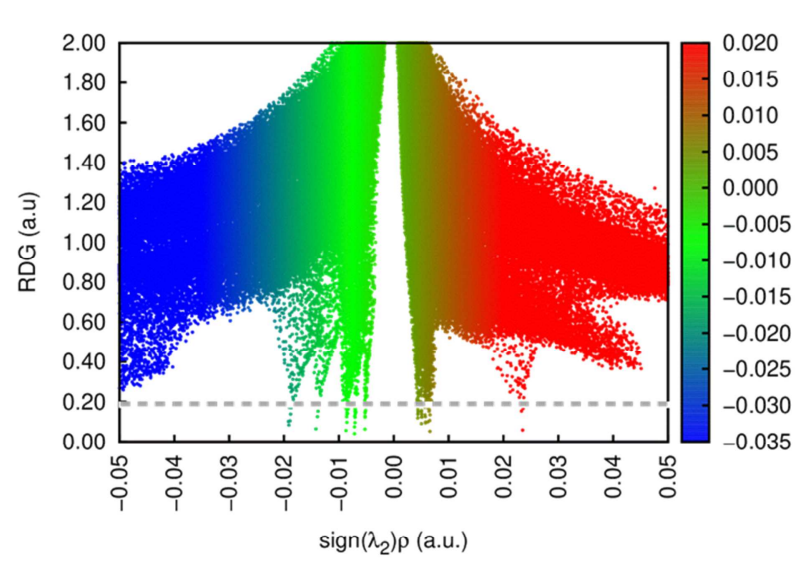

(b)

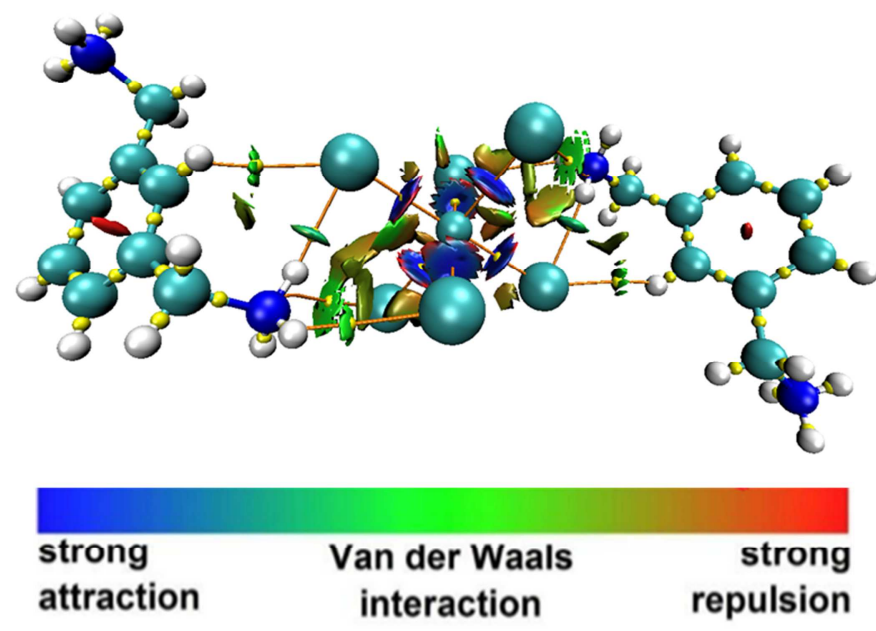

Fig. 8. Plots of the RDG versus the electron density $\rho$ multiplied by the sign of $\lambda_{2}$ (a) and color scaling of weak interactions (b) for the $\left(\mathrm{C}_{8} \mathrm{H}_{14} \mathrm{~N}_{2}\right)_{2} \mathrm{CdCl}_{6}$ compound. The surfaces are colored on a blue-green-red scale according to values of sign $\lambda_{2}$. Blue indicates strong attractive interactions and red indicates strong non-bonded overlap. 
(a)

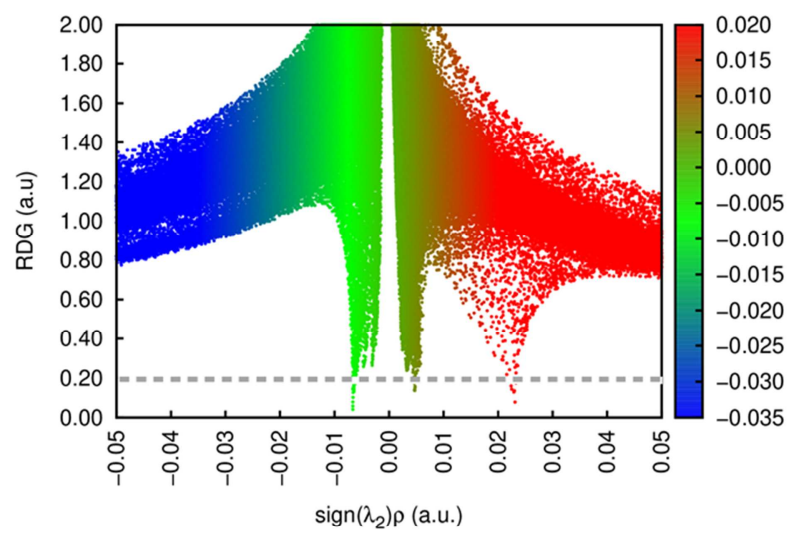

(b)

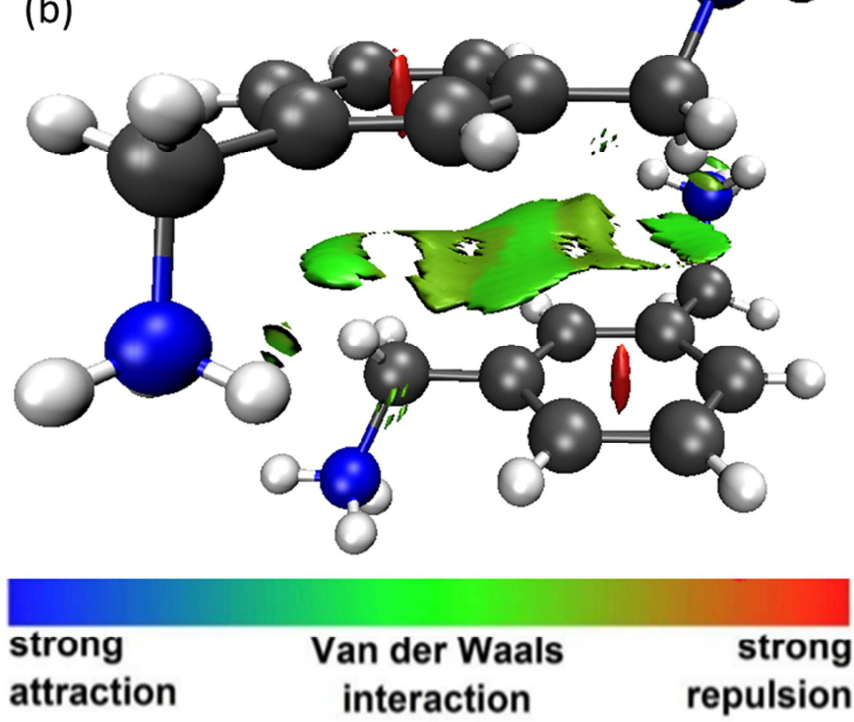

Fig. 9. Plots of the RDG versus the electron density $\rho$ multiplied by the sign of $\lambda_{2}$ (a) and color scaling of weak interactions (b) for the corresponding cation of $\mathrm{MXDCdCl}_{6}$. The surfaces are colored on a blue-green-red scale according to values of sign $\lambda_{2}$. Blue indicates strong attractive interactions and red indicates strong non-bonded overlap. 


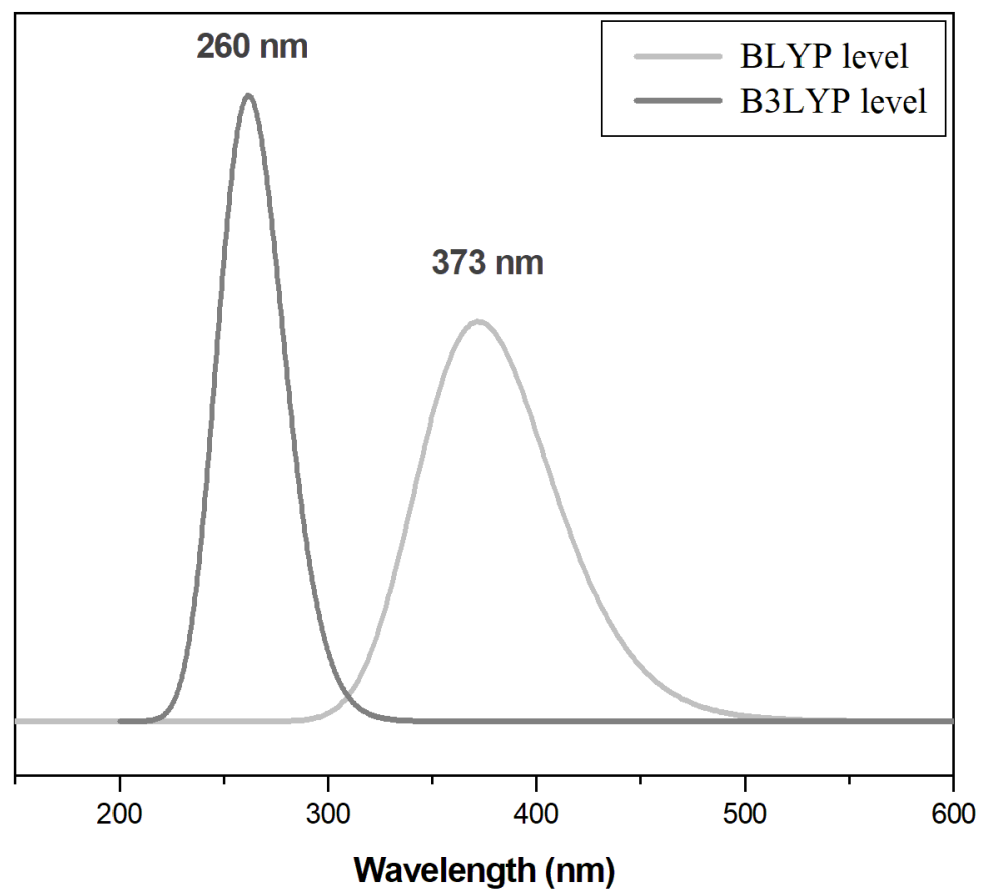

Fig. 10. Theoretical TD-DFT UV-Visible spectrum of the title compound at BLYP and B3LYP.
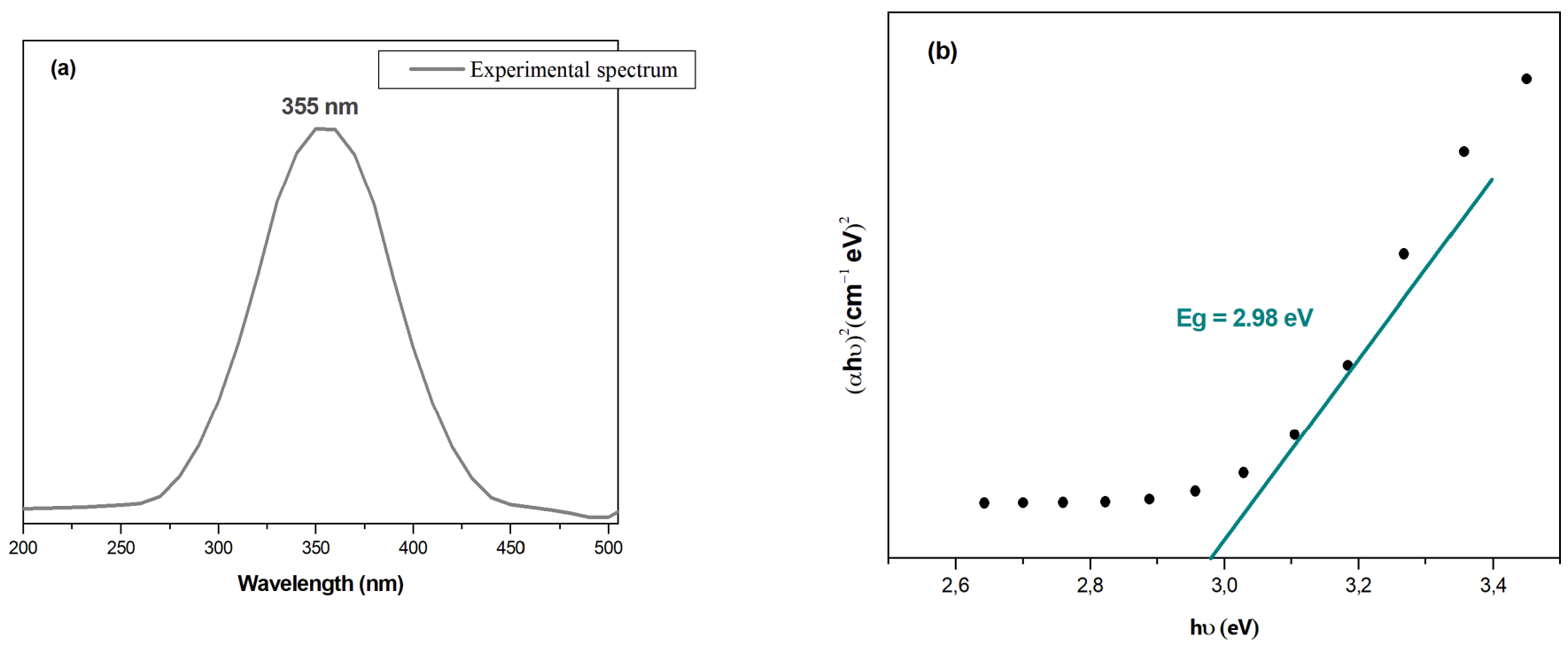

Fig. 11. Solid-state UV-Vis spectrum (a) of $\left(\mathrm{C}_{8} \mathrm{H}_{14} \mathrm{~N}_{2}\right)_{2} \mathrm{CdCl}_{6}$ and the energy gap (b) according to the Tauc model. 


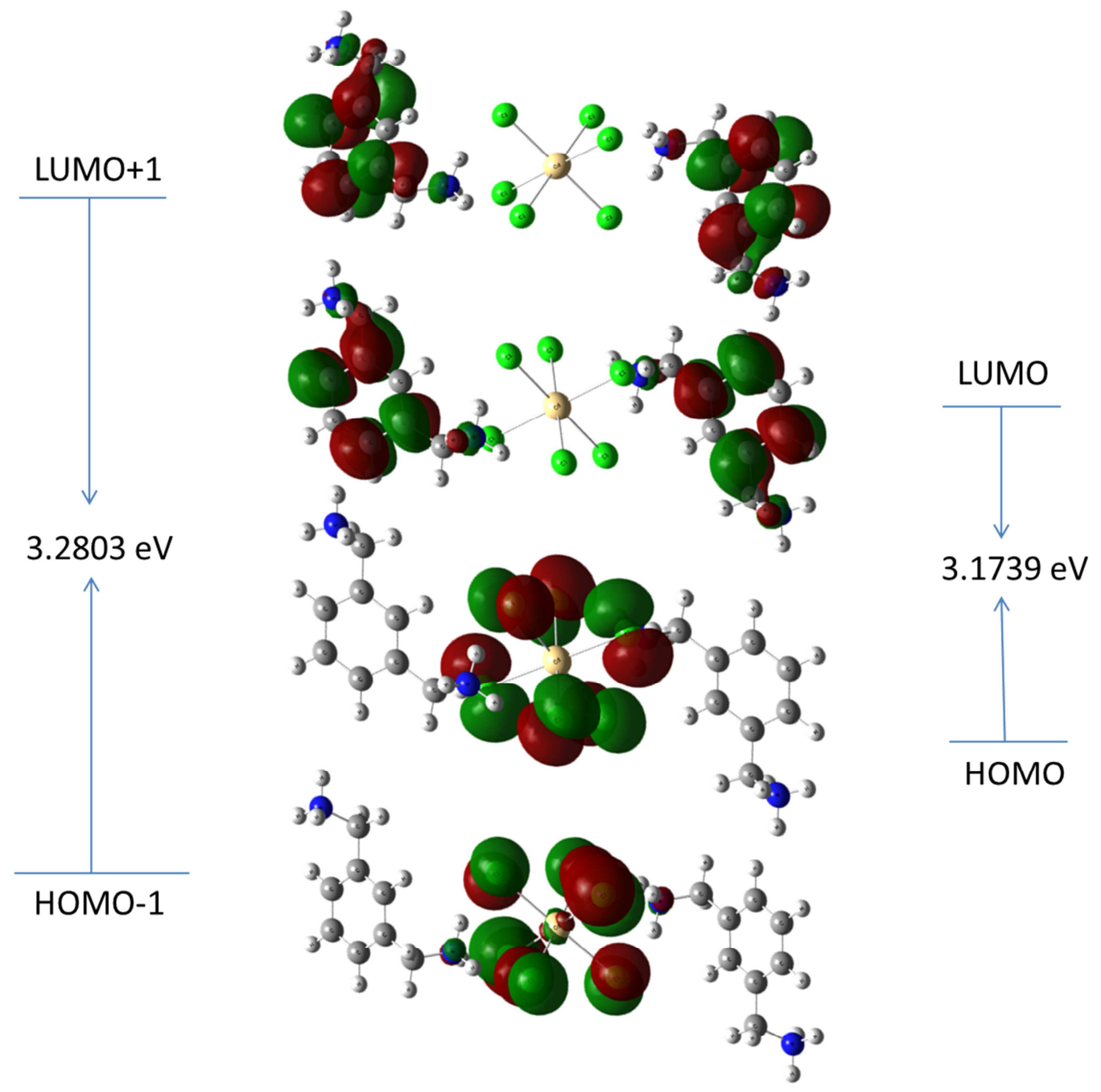

Fig.12. The frontier molecular orbitals of $\left(\mathrm{C}_{8} \mathrm{H}_{14} \mathrm{~N}_{2}\right)_{2} \mathrm{CdCl}_{6}$ molecule at DFT/LANL2DZ level. 
(a)

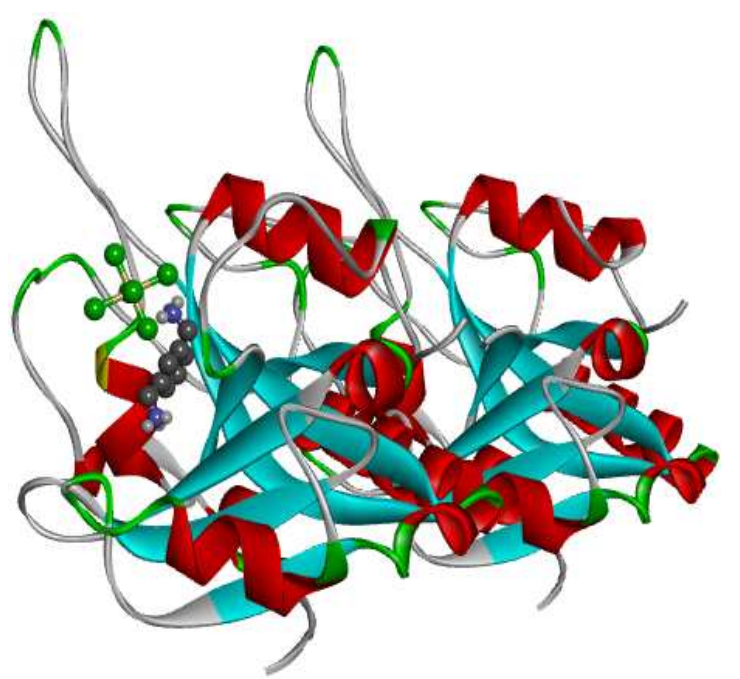

1XK9

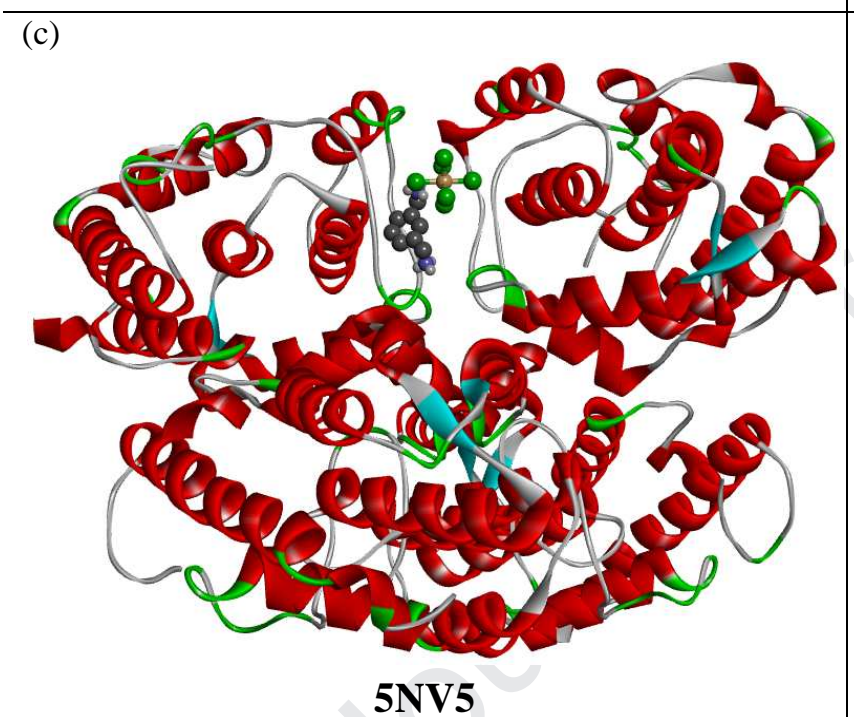

(b)

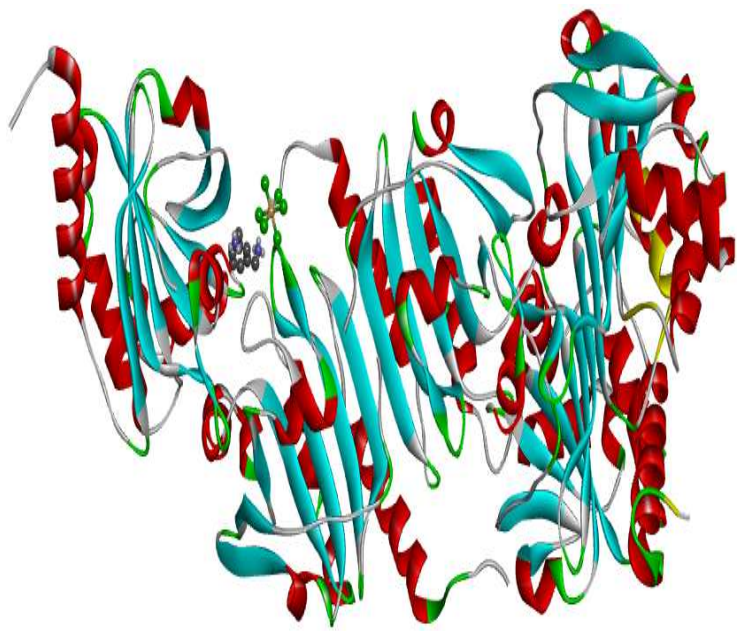

$5 Y 63$

(d)

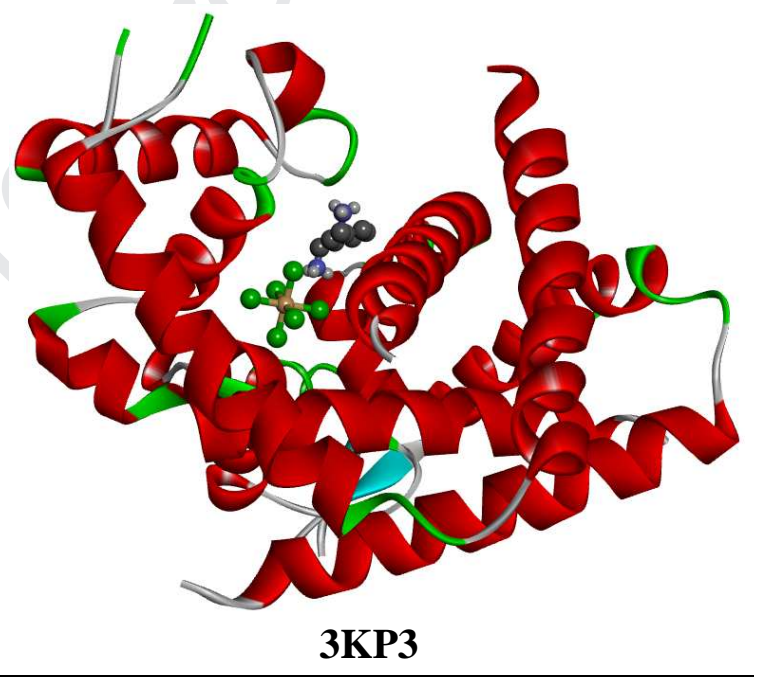

(f)

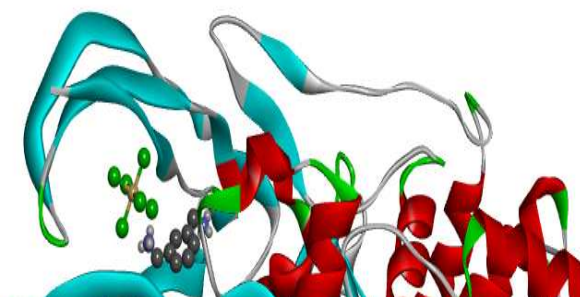

(4) Laj.

(1)

6G9P

(g)

(h) 

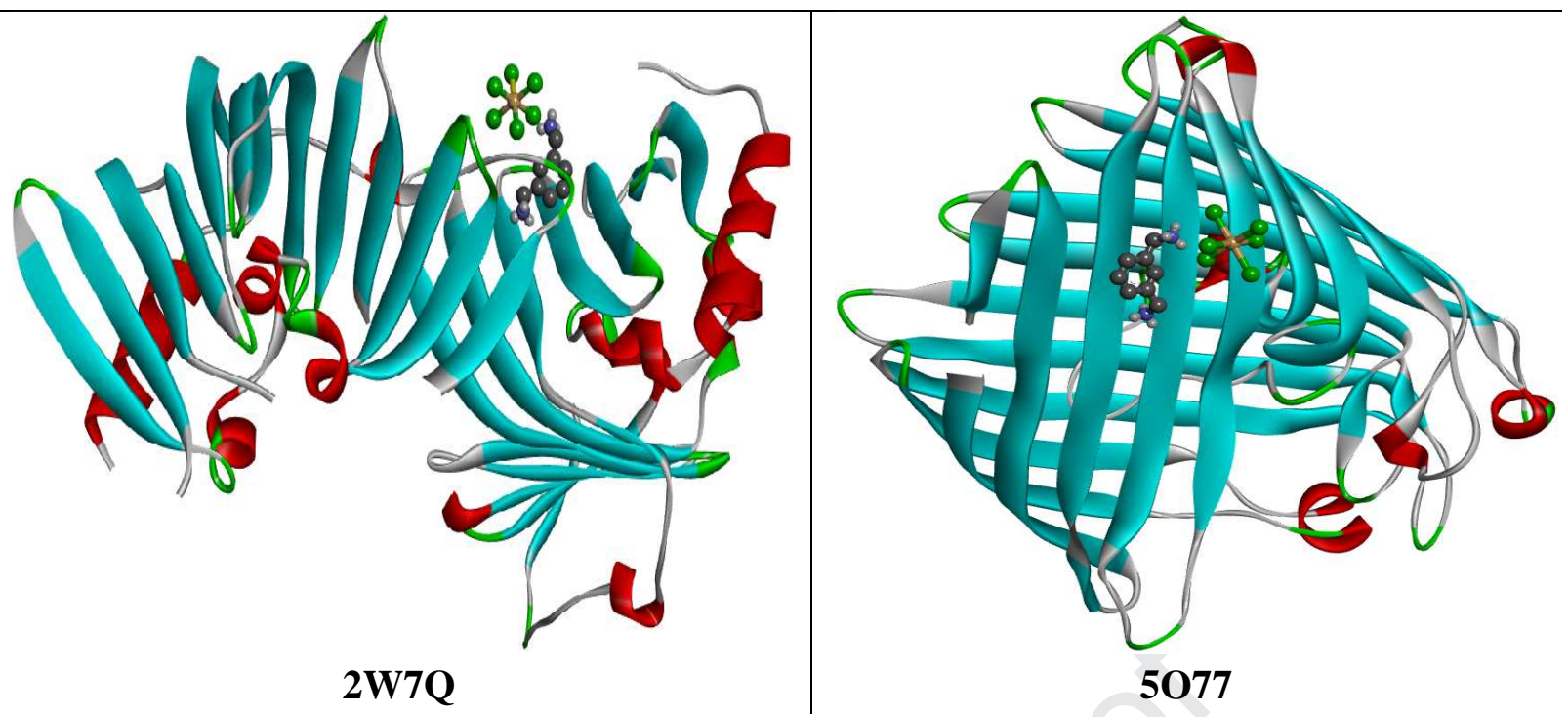

Fig. 13. The best docked poses of $\left(\mathrm{C}_{8} \mathrm{H}_{14} \mathrm{~N}_{2}\right)_{2} \mathrm{CdCl}_{6}$ compound with eight bacteria: 1XK9(a), 5Y63(b), 5NV5(c), 3KP3(d), 4OYH(e), 6G9P(f), 2W7Q(g), 5O77(h). 


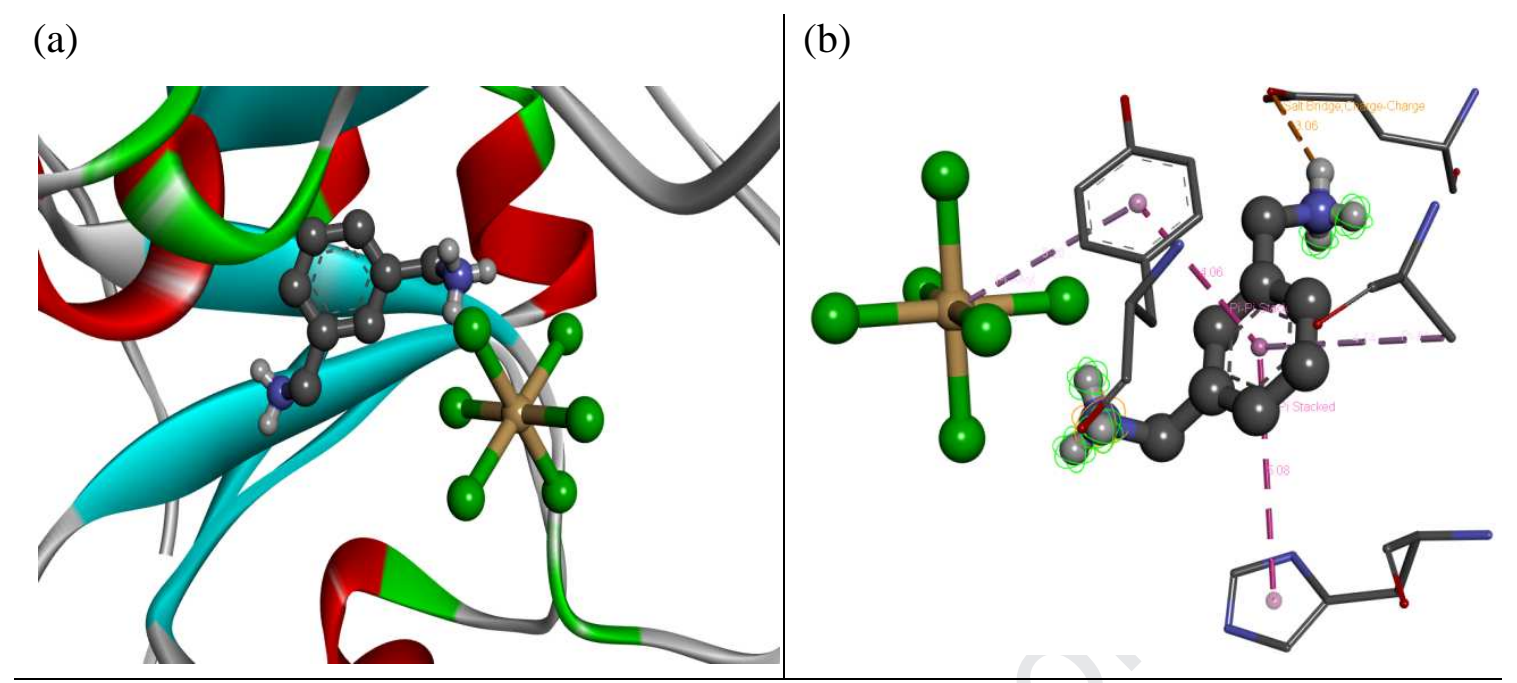

(c)

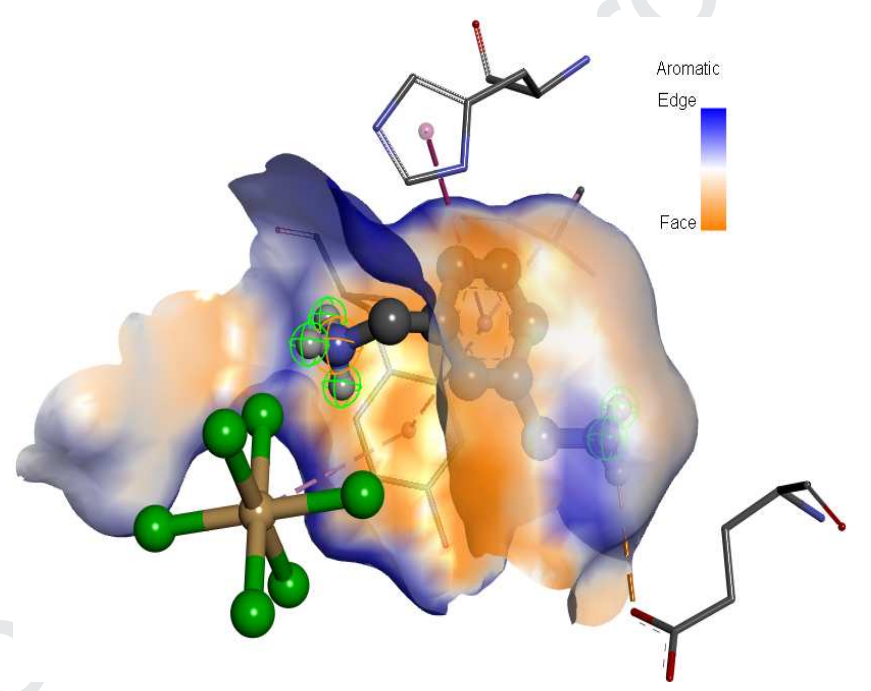

Fig. 14. Different types of interactions between $\left(\mathrm{C}_{8} \mathrm{H}_{14} \mathrm{~N}_{2}\right)_{2} \mathrm{CdCl}_{6}$ and $1 \mathrm{XK} 9$ bacteria. 
- $\quad$ Novel Cd(II) complex compound, $\mathrm{MXDCdCl}_{6}$, was synthesized.

- Optimized geometry and vibrational spectra were computed using DFT method.

- $\mathrm{MXDCdCl}_{6}$ was characterized by single crystal DRX and IR analyses.

- Charge transfer interactions were analyzed by AIM, RDG and HS analysis.

- Molecular docking studies confirmed the inhibitory activity of $\mathrm{MXDCdCl}_{6}$. 


\section{Declaration of interests}

ХThe authors declare that they have no known competing financial interests or personal relationships that could have appeared to influence the work reported in this paper.

$\square$ The authors declare the following financial interests/personal relationships which may be considered as potential competing interests: 